IZA DP No. 8246

Taxation and the Long Run Allocation of Labor: Theory and Danish Evidence

Claus Thustrup Kreiner Jakob Roland Munch

Hans Jørgen Whitta-Jacobsen

June 2014 


\title{
Taxation and the Long Run Allocation of Labor: Theory and Danish Evidence
}

\author{
Claus Thustrup Kreiner \\ University of Copenhagen, \\ CESifo and CEPR \\ Jakob Roland Munch \\ University of Copenhagen \\ and IZA \\ Hans Jørgen Whitta-Jacobsen \\ University of Copenhagen
}

Discussion Paper No. 8246
June 2014

IZA

P.O. Box 7240

53072 Bonn

Germany

Phone: +49-228-3894-0

Fax: +49-228-3894-180

E-mail: iza@iza.org

Any opinions expressed here are those of the author(s) and not those of IZA. Research published in this series may include views on policy, but the institute itself takes no institutional policy positions. The IZA research network is committed to the IZA Guiding Principles of Research Integrity.

The Institute for the Study of Labor (IZA) in Bonn is a local and virtual international research center and a place of communication between science, politics and business. IZA is an independent nonprofit organization supported by Deutsche Post Foundation. The center is associated with the University of Bonn and offers a stimulating research environment through its international network, workshops and conferences, data service, project support, research visits and doctoral program. IZA engages in (i) original and internationally competitive research in all fields of labor economics, (ii) development of policy concepts, and (iii) dissemination of research results and concepts to the interested public.

IZA Discussion Papers often represent preliminary work and are circulated to encourage discussion. Citation of such a paper should account for its provisional character. A revised version may be available directly from the author. 


\section{ABSTRACT \\ Taxation and the Long Run Allocation of Labor: Theory and Danish Evidence ${ }^{*}$}

Inspired by Hayek (1945), we study the distortionary effects of taxation on labor mobility and the long run allocation of labor across different profitable opportunities. These effects are not well detected by the methods applied in the large public finance literature estimating the elasticity of taxable income and quantifying the efficiency loss from taxation. Our analysis builds on a standard search theoretic framework where workers are continually seeking better paid jobs, but are also fired from time to time because of economic development and productivity shocks. We incorporate non-linear taxation into this setting and estimate the structural parameters of the model using employer-employee register based data for the full Danish population of workers and workplaces for the years 2004-2006. Our results indicate that along the intensive margin the Danish taxation generates an overall efficiency loss corresponding to a 12 percent reduction in total income. It is possible to reap $4 / 5$ of this potential efficiency gain by going from a high-tax Scandinavian system to a level of taxation in line with low-tax OECD countries such as the United States. The tax-responsiveness of labor mobility and allocation corresponds to an elasticity of taxable income with respect to the net-of-tax rate in the range $0.15-0.35$.

JEL Classification: J62, H24

Keywords: tax distortions, labor mobility, elasticity of taxable income

Corresponding author:

Jakob Roland Munch

Department of Economics

University of Copenhagen

Øster Farimagsgade 5

Building 26

1455 Copenhagen $\mathrm{K}$

Denmark

E-mail: Jakob.Roland.Munch@econ.ku.dk

\footnotetext{
* We thank participants at the Conference on the Economics of the Nordic Model in Oslo for helpful comments and suggestions. Financial support from the Economic Policy Research Network (EPRN) is gratefully acknowledged.
} 


\section{Introduction}

Hayek (1945) argues convincingly that the true merit of the capitalist market economy is its capability of continually responding to the ongoing changes in needs and possibilities by reallocating resources towards their best use. ${ }^{1}$ Prices convey information about productivity and scarcity of resources, and owners of resources react on price signals to obtain the highest possible returns, thereby collectively acting as an effective allocation device. According to this view, taxation distorts the functioning of the market economy by creating a wedge between the private return and the social return to a reallocation of resources, leaving socially desirable opportunities unexploited as a result. This type of tax distortion should be relevant for the labor market since employees change jobs many times during their career and economic incentives are a key determinant behind job changing decisions (Topel and Ward, 1992).

This paper studies the impact of taxation on the mobility and allocation of labor, and quantifies the efficiency loss from misallocation of labor caused by taxation. ${ }^{2}$ As will be explained below, labor mobility responses are fundamentally different from the hours-of-work responses of the basic labor supply model, which underlies the modern reduced-form empirical identification methods to measure behavioral responses to taxation. These methods are not well suited to detect mobility behavior, and therefore we apply a structural approach. Our analysis builds on a standard search theoretic framework, along the lines of Burdett (1978) and Christensen et al. (2005), where workers continually seek better paid jobs, but are also fired from time to time because of economic development and productivity shocks. We incorporate non-linear taxation into this setting and estimate the structural parameters of the model using employer-employee register based data for the full Danish population of workers and workplaces for the years 2004-2006. The estimated model is then used to examine the impact of different changes in the tax system, thereby characterizing the distortionary effects of taxation on the allocation of labor.

The overall tax distortion is identified by an experiment where all taxation along the intensive margin is replaced by lump sum taxation. For Denmark, with marginal tax rates ranging from 59 to 72 percent, the result is an increase in aggregate labor income of $1 / 4$, and an efficiency gain equal to 12 percent of initial income. This is a sizable, although not huge, efficiency loss, which should be balanced against the (non-measured) gains in social welfare from social insurance and equality achieved through high marginal taxation. Interestingly, it is possible to reap a very large part of the potential efficiency gain by going "half the way" and replace the current taxation

\footnotetext{
${ }^{1}$ The seminal article by Hayek was selected in 2011 to be one of the twenty most influential articles published by the American Economic Review in the entire history of the review.

${ }^{2}$ Our focus is on measuring behavioral responses to taxation and quantifying the efficiency loss from taxation. This is in line with the literature estimating the elasticity of taxable income. We do not attempt to quantify the trade-off between equality and efficiency (see Immervoll et al, 2007), but a normative tax analysis should, of course, balance the efficiency loss from taxation against the distributional consequences.
} 
with a flat tax rate of 30 percent on all income. This shift from a Scandinavian tax system with high marginal tax rates to a level of taxation in line with low-tax OECD countries such as the United States increases total income by 20 percent and yields an efficiency gain measured in proportion to initial income of 10 percent. The large effect on economic efficiency from going only "half the way" reflects the well-known result in the economics of taxation that the marginal efficiency loss is growing in the level of taxation. The structural approach enables us to derive this relationship between the marginal efficiency loss and the level of taxation, which turns out to be strongly convex with a Laffer rate around $2 / 3$. Finally, and most importantly, we compute the marginal tax distortion at the initial tax system and the elasticity of taxable income by looking at a small reduction in all marginal tax rates. ${ }^{3}$ The marginal efficiency effect is in this case equal to 87 percent of the (mechanical) loss in tax revenue, ${ }^{4}$ which translates into an elasticity of labor market income (taxable income) with respect to the net-of-tax rate of 0.3 . A number of sensitivity tests suggest that the estimate of the elasticity of taxable income due to mobility responses lies in the interval 0.15 to 0.35 .

Our results are related to the large public finance literature, recently surveyed by Saez et al. (2012), estimating the elasticity of taxable income with respect to the net-of-tax rate using tax return data. The ultimate goal of this literature is to estimate the 'true' underlying structural elasticity relevant for quantifying the efficiency losses from taxation. In two influential papers, Feldstein $(1995,1999)$ argued that the effects of the tax system on the reported income of the tax payers capture all relevant efficiency losses, and therefore the elasticity of taxable income is a sufficient statistic to compute the total tax distortion. However, the inclusion of taxable income responses due to tax avoidance and evasion behavior relies on strong assumptions (Chetty, 2009; Slemrod and Kopczuk, 2002), and recent empirical studies have increasingly focused on more narrow income concepts, mainly labor income as we also do, in order to isolate real responses (e.g. Chetty et al., 2011a; Kleven and Schultz, 2013).

Most of the literature has exploited variation in tax rates generated by tax reforms to identify the elasticity using difference-in-difference type methodologies where individual post-reform income levels are compared to pre-reform levels. Saez et al. (2012) conclude that an elasticity of taxable income of 0.25 seems to be a reasonable estimate from the existing studies and the recent empirical evidence for Denmark in Kleven and Schultz (2013), based on a series of tax reforms and a very rich administrative data set covering the entire Danish population, points to an elasticity of labor income around 0.1.

\footnotetext{
${ }^{3}$ More specifically, we consider a one percent increase in the net-of-tax rates.

${ }^{4}$ This also implies that the degree of self-financing, which measures the share of the mechanical tax revenue loss recouped by behavioral responses, equals 87 percent. For marginal reductions in taxation, the degree of self-financing is equal to the efficiency effect in proportion to the mechanical revenue change.
} 
Other recent studies have exploited bunching at the kink points of the tax system to identify the elasticity of taxable income (Saez, 2010; Chetty et al., 2011a, Bastani and Selin, 2014) and have found very small elasticities. Using Danish data, Chetty et al. (2011a) estimate an elasticity below 0.02. However, an important conclusion from this study is that the elasticity is larger when measured at larger kinks in the tax schedule. This strongly indicates that labor supply decision making is subject to short term frictions and adjustment costs, implying that the micro econometric identification methods in general underestimate the structural elasticity. After accounting for small frictions, corresponding to less than one percent of earnings, Chetty et al. (2011a,b) and Chetty (2012) conclude that the small elasticities obtained in the micro labor supply literature correspond to a structural intensive margin elasticity of around 0.3 , more in line with the elasticity found in the macro literature based on cross-country evidence.

Both the difference-in-difference type methods and the bunching method are unlikely to identify the labor allocation effects of taxation studied here. To see why, consider a change of the tax system where first all marginal tax rates are identical and then the marginal tax rates for income levels above a certain threshold are raised to a new, higher level, thus introducing tax progressivity with a kink-point in the tax schedule. According to a standard, hours-of-work labor supply model with heterogeneity in abilities, the behavior of workers with income below the threshold will be unaffected, while all workers with income above the threshold will reduce labor supply and income. Hence, it is possible to separate workers into distinct control and treatment groups depending on income levels before the tax change, and the tax increase makes workers pile up at the income level of the kink-point, thereby creating a discontinuity in the density function. This makes it possible to identify the underlying structural labor supply elasticity by measuring changes in income of the treatment group relative to the control group or by exploiting the bunching of individuals at the kink-point. In the search framework, both workers with income above the threshold and below it will reduce search effort. The reason that also workers below the threshold reduce effort is that their expected after-tax income gain from searching and climbing up the income ladder is reduced. Therefore, they do not constitute a well-defined control group and the kink in the tax schedule does not create an excess mass of individuals at the income threshold. ${ }^{5}$

To conclude, the otherwise strong empirical identification strategies normally used to identify income responses to taxation and the elasticity of taxable income are not well-suited to detect the income responses due to job mobility effects, and our estimates of the elasticity of taxable income and of the tax distortions of labor allocation, based on a structural approach, indicate that these job mobility effects are of a substantial magnitude.

\footnotetext{
${ }^{5}$ Another reason why the difference-in-difference types techniques are unlikely to detect the effects on search behavior is that job shifts and reallocation of labor are time-consuming processes, implying that it takes relatively long time for the economy to reach its new long run distribution of earnings after a tax reform.
} 
A few studies have analyzed the impact of taxation on job mobility decisions by looking at the mobility of people across states (Feldstein and Wrobel, 1998) and across countries (Kleven et al., 2014). The second study examines the impact of changes in the preferential tax regime for foreign researchers and high-income foreigners in Denmark and finds large effects on the number of highly paid foreigners. These types of studies are not comparable to our analysis of the impact of taxes on worker mobility and job allocation within a country, but they do show that taxation is important for the decision to shift job, as also found in our analysis. ${ }^{6}$ A study by Gentry and Hubbard (2004) looks at the impact of taxes on within-country job mobility. They show, using a reduced-form empirical analysis of the relationship between job turnover and tax rates in the US (together with a number of other co-variates), that job shifting is negatively correlated with tax rates and tax progression.

The paper proceeds as follows. Section 2 derives the relationship between taxation and the long run allocation of labor in a search theoretic model. Section 3 describes the estimation of the model. Section 4 uses the estimated model to quantify the distortions of taxation on the allocation of labor and derives the mobility-based elasticity of taxable income. Sensitivity analyses are reported in Section 5, and Section 6 concludes.

\section{Theory}

In this section we set up a model of job search, labor allocation and taxation. It is an on-the-job search model similar to Burdett (1978) and Christensen et al. (2005), but with discrete wage distribution, zero discounting and including non-linear taxation. The assumption of a discrete wage distribution gives a direct correspondence between the theoretical model and the empirical implementation. The assumption of no discounting simplifies our analysis of tax reforms considerably since we only need to consider the influence of a reform on the long run, steady state outcome to determine its implications on aggregate welfare/economic efficiency.

\section{$2.1 \quad$ Fundamentals of the model}

We consider a worker who is either employed in one out of a number of potential employment relationships/jobs $(i=1, \ldots N)$ paying different wages, or without any job $(i=0)$. When employed the worker may lose his job due to exogenous, random job destruction shocks. The worker may engage in search activity to find a better paid job when employed, and to find an employment opportunity when not employed. Thus, search leads to job mobility and labor reallocation.

\footnotetext{
${ }^{6}$ Note that the cross-country mobility decisions are related to the variation in average tax rates across countries, implying that a replacement of taxes that are increasing in income with a poll tax does not remove tax distortions in cross-country mobility decisions.
} 
In job $i$, the worker earns income $w_{i}$, where $w_{1}<\cdots<w_{N}$. In the non-employment state, $i=0$, the worker obtains an income equivalent $w_{0}$ of leisure and home production. The net-of-tax income in job $i$ equals $w_{i}-T_{i}$, where $T_{i}$ is a tax-benefit function that includes all taxes and transfers, and $-T_{0}$ is the net benefit in the non-employement state. We define marginal tax rates as $m_{i}=\left(T_{i+1}-T_{i}\right) /\left(w_{i+1}-w_{i}\right)$ for $i=1, \ldots, N-1$, and $m_{0}=\left(T_{1}-T_{0}\right) / w_{1}$, where it is assumed that $0 \leq m_{i}<1$ for all $i$. We disregard low-wage job offers that would never be accepted by the worker and assume $w_{1}-T_{1} \geq w_{0}-T_{0}$.

In state $i$, the worker decides on a search effort level $s_{i} \geq 0$. The cost of search effort is given by $c(s)$, where $c(0)=c^{\prime}(0)=0, c^{\prime}>0$, and $c^{\prime \prime}>0$. The worker receives job offers with Poisson frequency $\lambda s_{i}$, where $\lambda$ is a positive parameter. The wage rate of a job offer, $w_{j}$, is drawn from a given discrete probability distribution with probability $p_{h}$ of $w_{h}$ for $h=1, \ldots, N$. The cumulative distribution is $P_{i}=\sum_{j=1}^{i} p_{j}$. The worker may either accept the job offer and shift to job $j$, or reject the offer and stay in state $i$. Since the effort cost function $c(s)$ and the job offer distribution $P$ are independent of the initial state $i$, it follows that a worker will accept a job offer if $w_{j} \geq w_{i}$. A worker who does not receive a job offer stays at state $i$.

When employed, the worker is exposed to a job destruction shock representing changing economic circumstances. At the Poisson frequency $\delta$, the worker loses his current job, becomes non-employed and must wait for new job offers. The total job separation rate from job $i$ is then $\delta+\lambda s_{i}\left(1-P_{i}\right)$. If non-employed, the worker receives job offers drawn from the $P$-distribution with Poisson frequency $\lambda s_{0}$, and accepts any job offer $w_{j}$ because of the assumption $w_{j}-T_{j} \geq w_{0}-$ $T_{0}$.

The income net of taxes and search cost in state $i$ equals $w_{i}-T_{i}-c\left(s_{i}\right)$, and the worker decides on search effort in all states to maximize intertemporal utility defined as the expected present value of income net of taxes and search costs.

\subsection{Optimal search behavior}

A given search behavior, $s_{0}, s_{1}, \ldots, s_{N}$, results in a certain steady state distribution over states $i=0,1, \ldots, N$, determining the share of time the worker will be non-employed, $i=0$, and in jobs $i=1, \ldots, N$, respectively, in the long run. With many identical workers this steady state distribution would also be the long run distribution of workers over states at any given time. Let $u$ be the steady state rate of non-employment, and let $g_{i}$ be the steady state fraction of employment in job $i=1, \ldots, N$, where $\sum_{j=1}^{N} g_{i}=1$. The cumulative distribution is $G_{i}=\sum_{j=1}^{i} g_{i}$.

The assumption of no discounting implies that the intertemporal utility $W$ of the worker equals the expectation of income net of tax and search cost with respect to the steady state distribution 
of employment and wages:

$$
W=u\left[w_{0}-T_{0}-c\left(s_{0}\right)\right]+(1-u) \sum_{j=1}^{N}\left[w_{j}-T_{j}-c\left(s_{j}\right)\right] g_{j} .
$$

The worker maximizes $W$ with respect to $s_{0}, \ldots, s_{N}$. The first-order conditions are

$$
\begin{aligned}
& \frac{d W}{d s_{0}}=-u \cdot c^{\prime}\left(s_{0}\right)+\frac{\partial u}{\partial s_{0}}\left[w_{0}-T_{0}-c\left(s_{0}\right)-\sum_{j=1}^{N}\left[w_{j}-T_{j}-c\left(s_{j}\right)\right] g_{j}\right]=0, \\
& \frac{d W}{d s_{i}}=-(1-u) c^{\prime}\left(s_{i}\right) g_{i}+(1-u) \sum_{j=1}^{N}\left[w_{j}-T_{j}-c\left(s_{j}\right)\right] \frac{\partial g_{j}}{\partial s_{i}}=0 \text { for } i=1, \ldots, N .
\end{aligned}
$$

To find the partial derivatives $\partial u / \partial s_{0}$ and $\partial g_{j} / \partial s_{i}$, we must determine how the steady state distribution depends on behavior. The flow out of non-employment equals $u \lambda s_{0}$, and the flow into non-employment is $(1-u) \delta$. In steady state these flows are identical giving

$$
u=\frac{\delta}{\lambda s_{0}+\delta} .
$$

Consider the set of jobs $I=\{1, \ldots, i\}$. According to the steady state distribution, the worker will spend the fraction $(1-u) G_{i}$ of time in set $I$. The flow into $I$ comes from non-employment and equals $u \lambda s_{0} P_{i}$. The flow out of $I$ to non-employment is $\delta(1-u) G_{i}$, and the flow to higher wages is $(1-u) \sum_{j=1}^{i} g_{j} \lambda s_{j}\left(1-P_{i}\right)$. The condition that flow out equals flow in is

$$
\delta(1-u) G_{i}+(1-u) \sum_{j=1}^{i} \lambda s_{j} g_{j}\left(1-P_{i}\right)=u \lambda s_{0} P_{i},
$$

which together with equation (4) gives

$$
G_{i}=P_{i}-\frac{1}{\delta}\left(1-P_{i}\right) \sum_{j=1}^{i} \lambda s_{j} g_{j},
$$

showing that $G$ stochastically dominates $P$ because search on-the-job implies that the worker climbs up the income ladder. Note also that an increase in $s_{i}$ implies that the post-change distribution stochastically dominates the pre-change distribution.

From the first-order conditions (2) and (3) and the relationships (4) and (5) characterizing the steady state distribution, we may derive the following formulas for the optimal search behavior (Appendix A)

$$
s_{N}=0
$$

and

$$
\begin{aligned}
c^{\prime}\left(s_{i}\right)= & \lambda \frac{\left(w_{i+1}-T_{i+1}\right)-\left(w_{i}-T_{i}\right)-\left[c\left(s_{i+1}\right)-c\left(s_{i}\right)\right]+s_{i+1} c^{\prime}\left(s_{i+1}\right)-s_{i} c^{\prime}\left(s_{i}\right)}{\delta}\left(1-P_{i}\right) \\
& +c^{\prime}\left(s_{i+1}\right),
\end{aligned}
$$


for $i=0,1, \ldots, N-1$. This gives a recursive determination of optimal effort levels. Given $s_{N}=0$, equation (7) implicitly yields a solution for $s_{N-1}$, and given this $s_{N-1}$, it gives a solution for $s_{N-2}$ and so on.

\subsection{Effects of tax reforms on search behavior, labor allocation and eco- nomic efficiency}

To illustrate how taxes work in this setting, we now consider small tax reforms formalized as infinitesimal changes in the tax liabilities, $d T_{i}$, for all $i=0, \ldots N$. It is seen directly from equation (7) that search behavior only depends on taxation through $T_{i+1}-T_{i}$, and therefore only on the marginal tax rates since $T_{i+1}-T_{i}=m_{i}\left(w_{i+1}-w_{i}\right)$.

From $s_{N}=0$ follows $d s_{N}=0$. To obtain the effects on search effort levels for $i=0,1, \ldots, N-1$, we differentiate equation (7). This gives

$$
\left[\frac{\delta}{\lambda\left(1-P_{i}\right)}+s_{i}\right] d s_{i} c^{\prime \prime}\left(s_{i}\right)-\left[\frac{\delta}{\lambda\left(1-P_{i}\right)}+s_{i+1}\right] d s_{i+1} c^{\prime \prime}\left(s_{i+1}\right)=-d m_{i}\left(w_{i+1}-w_{i}\right) .
$$

Inspection of equation (8) shows that if the marginal tax rate is increased at income level $w_{j}$ for some $j \leq N-1$, and unchanged everywhere else, then search effort at all wage levels up to and including $j$ decreases, while effort is unchanged at higher income levels, and the worker's expected (pre tax) income decreases accordingly. This is in contrast to a standard hours-of-work, labor supply model, where the worker's behavior and hence income is only affected if the worker happens to have a pre-change income level exactly where the marginal tax rate is changed.

In order to understand the empirical challenges of identifying the behavioral responses to taxation in a setting with search and labor mobility, consider a change of the tax system where first all marginal tax rates are identical, and then the marginal tax rates for income levels above a certain threshold are raised to a new, higher value, thus introducing tax progression with a kinkpoint in the tax schedule. In a standard hours-of-work, labor supply model, all workers with income below the kink-point will keep hours and income unchanged, while all workers with income above it will decrease hours to an extent that will keep income at or above the kink-point. According to such a model, the tax experiment would split workers into a control group of unaffected (low income) workers and a treatment group of affected (high income) workers, and the post change tax system would make workers pile up at the income level of the kink-point thereby creating a discontinuity in the density function. This implies that it is possible to identify empirically

the behavioral responses by comparing treatment and control groups using difference-in-difference type techniques or by exploiting the bunching at the kink-point, as done in the literature surveyed in the Introduction.

In the model studied here, the experiment would affect behavior at all income levels, also below the kink-point. Hence, although the model does create an income distribution with some workers 
above and some workers below the kink-point, these groups would not constitute a treatment and a control group, respectively. ${ }^{7}$ Moreover, there would not be any bunching at the kink-point of the new tax system because search intensities decrease everywhere, and not just above the kink point. This explains why these two commonly used empirical methods cannot be expected to identify the behavioral effects of taxation on labor mobility and, as a consequence, the tax distortion of the allocation of labor.

Next, we look at the impact of taxation on economic efficiency. The dead-weight loss/excess burden of taxation is defined as

$$
D=\tilde{W}-W-R,
$$

where $W$ is the private welfare of equation (1) at the given tax system, $\tilde{W}$ is private welfare in the absence of taxation, and $R$ is the tax revenue defined as

$$
R=u \cdot T_{0}+(1-u) \sum_{i=1}^{N} T_{i} g_{i}
$$

where $u$ and $g_{1}, \ldots, g_{N}$ are the distributional parameters at the given tax system.

In Section 3 and Section 4, we quantify the distortionary effects of taxation by estimating the structural parameters of the model and then compute directly the change in $W, R$ and $D$ caused by different types of tax reforms. To illustrate the main determinants of the efficiency effects, we first analyze theoretically the impact of small reforms.

The change in the dead-weight loss of taxation from a small change in the tax system is equal to (see Appendix B)

$$
d D=\left[\sum_{i=1}^{N}\left(T_{i}-T_{0}\right) g_{i}\right] \frac{\partial u}{\partial s_{0}} d s_{0}-(1-u) \sum_{j=1}^{N} \sum_{i=j}^{N}\left(T_{i}-T_{j}\right) \frac{\partial g_{i}}{\partial s_{j}} d s_{j},
$$

where $d s_{i}$ denote the changes in search effort levels induced by the tax change. This result reflects the general insight from the theory of taxation that the efficiency effects of small policy reforms are given simply by the behavioral revenue effects. ${ }^{8}$ To see that this is the case, consider a reform that reduces marginal taxes and increases search intensities at all states except $N$. This will move a probability mass $g_{i}\left|\partial u / \partial s_{0}\right| d s_{0}$ from non-employment to job $i$, which will increase tax revenue by $\left[T_{i}-T_{0}\right] g_{i}\left|\partial u / \partial s_{0}\right| d s_{0}$. This explains the first term on the right hand side of (11). In the same vein, the increased search effort in job $j \in\{1, \ldots, N-1\}$ will move probability

\footnotetext{
${ }^{7}$ In a homogeneous agent model there could never be a treatment and a control group, but in a heterogeneous agent version of the mobility model, where wage differences were partly due to differences in ability and partly due to differences in the workers' positions in the mobility cycle, the distinction between treatment and control group would still not be clear. For instance, workers with current income (just) below the kink-point could be in that position either due to relatively low ability or due to a temporarily low position in the mobility cycle. In the first case they would not be affected by the tax experiment, in the second case they would.

${ }^{8}$ This insight applies to any model where individuals optimize and the only source of inefficiency is distortionary taxation (Kleven and Kreiner, 2005).
} 
mass $(1-u)\left|\partial g_{i} / \partial s_{j}\right| d s_{j}$ from job $j$ to job $i$ where $i>j$, implying an indirect tax effect of $\left[T_{i}-T_{j}\right](1-u)\left|\partial g_{i} / \partial s_{j}\right| d s_{j}$. This explains the second term on the RHS of (11). All in all, the behavioral effect on tax revenue comes from the way the reform induces people to move from states with lower net taxes to states with higher net taxes.

If the initial tax system is linear, $T_{i}=T_{0}+m \cdot w_{i}$ for $i \geq 1$, and we consider a uniform change $d m$ in all marginal tax rates, then the formula (11) simplifies to (Appendix C)

$$
\frac{d D}{Y}=\frac{m}{1-m} \cdot \varepsilon \cdot d m
$$

where

$$
Y=(1-u) \sum_{j=1}^{N} w_{j} g_{j}
$$

is taxable income (average earned income) and

$$
\varepsilon=\frac{\partial Y}{\partial(1-m)} \frac{1-m}{Y}
$$

is the elasticity of taxable income with respect to the net-of-tax rate, $1-m$. Equation (12) is a standard elasticity formulation of the marginal effect on economic efficiency where in our context $\varepsilon$ is a 'mobility elasticity': The percentage increase in income caused by intensified search and thereby increased labor mobility for a one percent increase in the net of tax rate.

\section{Empirical implementation}

This section first describes the institutional features of the Danish labor market and our matched employer-employee data. Next, we outline some identification assumptions, and finally, the structural estimation approach is described. We follow the approach of Christensen et al. (2005) and estimate directly the wage distribution of job offers, $P_{i}$, the initial tax-benefit function, $T_{i}$, the job offer probability parameter, $\lambda$, the mobility effort cost function, $c(s)$, and the job destruction rate, $\delta$.

\subsection{The Danish labor market}

Unlike many continental European countries, Denmark has a very flexible labor market (see, e.g., Botero et al. 2004). Employment protection is weak and turnover rates and average tenure are in line with those of the Anglo-Saxon countries. While most workers are in unions, wage formation has increasingly become more flexible as wage bargaining has been decentralized from the sector level to the firm level. In the late 1980s most wage contracts in the private labor market were negotiated at the sector level, but in our base sample year, 2005, less than $20 \%$ of the labor market was still covered by centralized wage bargaining. Instead wage contracts are negotiated 
either exclusively at the firm level or as a wage floor negotiated at the sector level combined with subsequent negotiations at the firm level. Dahl et al. (2012) shows that this decentralization process has increased wage dispersion in the Danish labor market such that wages to a larger degree reflect local firm-level conditions.

\subsection{Data description and empirical identification assumptions}

We use data for the full population of workers and workplaces in Denmark for the years 2004-2006. The data are drawn from the Integrated Database for Labour Market Research (IDA), which is a longitudinal employer-employee register based data set maintained by Statistics Denmark. Workers and workplaces are linked and uniquely identified over time such that worker transitions in and out of the workplace may be tracked. ${ }^{9}$ In a specific week in each of the years 2004, 2005 and 2006, we know which workers were employed at each workplace.

In the following we focus on workers aged 18-65 years and employed in private sector workplaces in 2005. For each workplace we register its size (the number of employees in 2005), the average wage rate of the employees, the number of "stayers" (the workers employed at the workplace in 2005 who are still employed at it in 2006), the number of "new hires" (the workers employed at the workplace in 2005 who were not employed there in 2004), and the number of "new hires from non-employment" (the workers employed at the workplace in 2005 who were not employed at any workplace in 2004, thus coming from non-employment or non-participation).

The wage rate of a worker is calculated as annual labor income (including mandatory pension fund payments) divided by annual hours. To reduce the impact of potential measurement errors in the calculation of workplace average wages, we exclude all observations in the top percentile (wage rates above DKK 714) in the wage distribution. In addition, wages below DKK 90 are dropped. A cut-off wage rate $w_{1}$ of DKK 90 corresponds approximately to the minimum wage floor negotiated at the sector level in 2005. This is also evident from the empirical wage distribution which exhibits a hump around DKK 90. In Section 5 on robustness, we report the results from a sensitivity analysis where the model is estimated with different cut-offs in the bottom of the wage distribution.

Following Christensen et al. (2005), we associate to each worker at a workplace the workplace's average hourly wage rate. This average wage rate then corresponds to the wage $w_{i}$ in job $i$ of the theoretical model. The reason for this approach is that it is the firm component in wages that matters for job-to-job mobility in on-the-job search models. Under the assumption that worker and firm components in the wage are independent, firm-level average wages correspond to the firm

\footnotetext{
${ }^{9}$ In IDA a workplace is an establishment defined by a geographical location. Most often one firm has only one workplace, but few (larger) firms have several and thus split up in several workplaces in the data.
} 
component plus noise.

In the resulting data set, we have 126,400 workplaces with an average size of 11 employees, an average number of stayers of 7.7, an average wage rate of DKK 197.6, an average number of new hires of 3.3, with 0.6 of these being new hires from non-employment, cf. Table 1.

\begin{tabular}{lrrrr}
\multicolumn{4}{c}{ Table 1. Workplace summary } & Statistics \\
\hline \hline Variables & Mean & Median & Min & Max \\
\hline Size & 11.0 & 4.0 & 1.0 & 4141.0 \\
Stayers & 7.7 & 2.0 & 0.0 & 3677.0 \\
Wage & 197.6 & 183.2 & 90.0 & 714.1 \\
New hires & 3.3 & 1.0 & 0 & 2233.0 \\
- from non-employment & 0.6 & 0.0 & 0.0 & 158.0 \\
\# workplaces & \multicolumn{4}{c}{126,400} \\
\hline \hline
\end{tabular}

In the empirical implementation we need data for marginal tax rates. We use the empirical tax function for Denmark for 2006 constructed by Kleven and Kreiner (2006), which provides effective marginal tax rates as a function of annual labor income. The effective marginal tax rate at a given annual income level includes income taxes, indirect taxes and the marginal claw-back on any benefits that the individual is receiving. To apply this tax function to our 2005 data, we first deflate it by the overall growth rate in the average annual labor income between 2005 and 2006 . Next, we convert the hourly wage rates in the data into annual labor incomes by multiplying it with the median annual hours worked in the data (1,660 hours). In this way, we assign an effective marginal tax rate to each hourly wage from DKK 90 up to DKK 714 as illustrated in Figure 1. These correspond to $m_{1}, \ldots, m_{N}$. For $m_{0}$ we use in our baseline estimation the value 0.59 , which is the marginal tax rate of the lowest possible wages around DKK 90. In the sensitivity analysis in Section 5 , we consider also a higher value of $m_{0}$ in order to account for the loss of unemployment benefits when entering the labor market.

The effective marginal tax rates are sufficient information to estimate the model and to perform subsequent policy analysis because (as mentioned) behavior only depends on taxation through the marginal tax rates. We can therefore construct a tax function from the marginal tax rates by choosing $T_{0}$ arbitrarily and let $T_{1}=T_{0}+m_{0} w_{1}$ and $T_{i+1}=T_{i}+m_{i}\left(w_{i+1}-w_{i}\right), i=1, \ldots, N-1$.

We assume that workers are indifferent between working at the lowest wage level in the wage distribution and not working at all, $w_{1}-T_{1}=w_{0}-T_{0}$, which implies $w_{0}=w_{1}-\left(T_{1}-T_{0}\right)=$ $\left(1-m_{0}\right) w_{1}$. With $m_{0}=0.59$ and $w_{1}=90$, we obtain $w_{0}=36.9$. Hence, the value of leisure, home production etc. corresponds to an hourly wage of DKK 36.9.

Again following Christensen et al. (2005), the wage offer distribution, $P_{i}$, is defined as the distribution of firm-specific average wages for persons entering firms in 2005 from non-employment in 2004. Thus, $P_{i}$ is constructed by weighting the firm-specific wage of firm $i$ by the fraction of all workers hired from non-employment by firm $i$. This distribution may be compared to the 


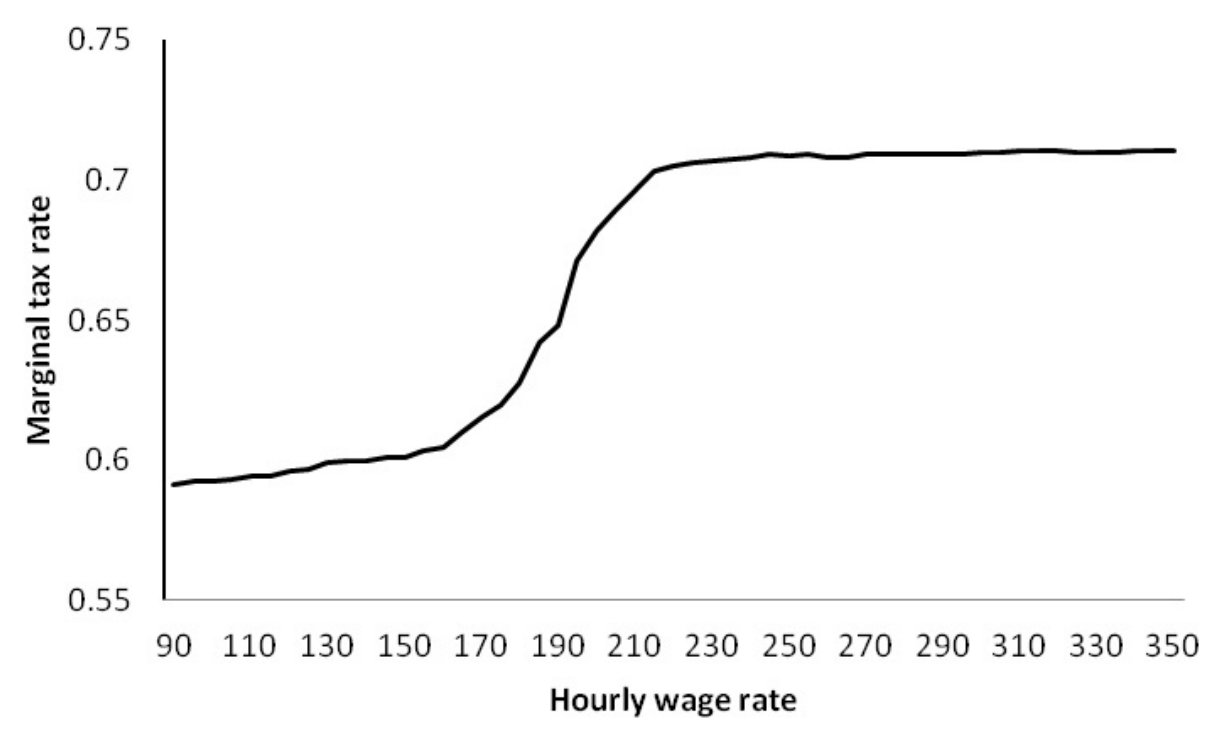

Figure 1: Effective marginal tax rates as a function of hourly wage rates.

distribution of earned average wages for all workers, and as expected from equation (5) the earned wage distribution is stochastically dominating the offered wage distribution, cf. Figure 2.

Finally, to identify the model, we assume that the mobility cost function is isoelastic:

$$
c(s)=c_{0} \frac{s^{1+1 / \gamma}}{1+1 / \gamma}
$$

with the parameters $c_{0}$ and $\gamma$.

\subsection{Structural Estimation}

Using the cost function (15), we may rewrite equation (7) determining the optimal search levels as

$$
\begin{aligned}
\left(\lambda s_{i}\right)^{1 / \gamma}= & \frac{\alpha\left[\left(w_{i+1}-T_{i+1}\right)-\left(w_{i}-T_{i}\right)\right]+\frac{1}{1+\gamma}\left[\left(\lambda s_{i+1}\right)^{1+1 / \gamma}-\left(\lambda s_{i}\right)^{1+1 / \gamma}\right]}{\delta}\left(1-P_{i}\right) \\
& +\left(\lambda s_{i+1}\right)^{1 / \gamma}
\end{aligned}
$$

where $\alpha=\frac{\lambda^{1+1 / \gamma}}{c_{0}}$. The levels of search effort determine the job separation rates which, for a firm paying the wage level $w_{h}$, equals

$$
d_{h}=\delta+\lambda s_{h}\left(1-P_{h}\right)
$$

where $s_{h}$ is the optimal mobility effort at wage $w_{h}$. 


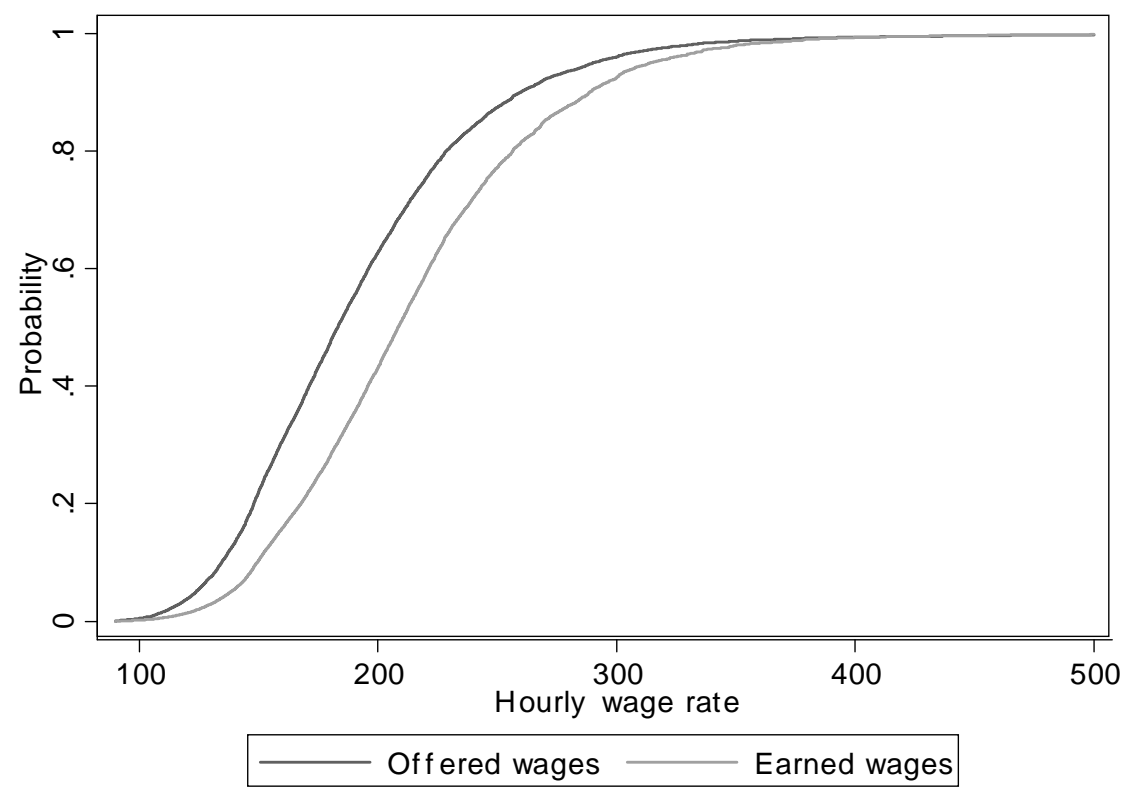

Figure 2: Offered wage and earned wage distributions

The key parameters $\alpha, \delta$ and $\gamma$ are estimated in the following way. For given values of $\alpha, \delta$ and $\gamma$ (keeping fixed the set of $w_{i}$ and $P_{i}$ and $T_{i}$ ), and starting with $\lambda s_{N}=0$, equation (16) determines recursively $\lambda s_{N-1}, \ldots, \lambda s_{1}, \lambda s_{0}$. This means that equation (16) yields a functional relationship from the triplet $(\alpha, \delta, \gamma)$ to the effort levels $\left(\lambda s_{0}, \lambda s_{1}, \ldots, \lambda s_{N}\right)$, and then to the hazard rates $d_{h}$ of equation (17). In the data, we observe for each workplace $h$ the number of employees $n_{h}$ in 2005 , and the number of stayers $x_{h}$ from 2005 to 2006. Given the separation rate $d_{h}$, the Poisson probability of zero separations within one period is $e^{-d_{h}}$, which is the probability of staying. Hence, the probability of $x$ stayers within a year is given by the binomial distribution function

$$
\operatorname{Pr}\left(x_{h}=x \mid n_{h}, d_{h}\right)=\left(\begin{array}{c}
n_{h} \\
x
\end{array}\right) e^{-d_{h} x}\left(1-e^{-d_{h}}\right)^{n_{h}-x}
$$

and the probability of observing $x_{1}, \ldots, x_{H}$ over all firms is

$$
L(\alpha, \delta, \gamma)=\prod_{h=1}^{H}\left(\begin{array}{c}
n_{h} \\
x_{h}
\end{array}\right) e^{-d_{h} x}\left(1-e^{-d_{h}}\right)^{n_{h}-x},
$$

where $d_{h}=\delta+\lambda s_{h}\left(1-P_{h}\right)$ depends directly on $\delta$ and, through $\lambda s_{h}$, on $(\alpha, \delta, \gamma)$. The log likelihood equals

$$
\ln L(\alpha, \delta, \gamma)=\sum_{h=1}^{N}\left[\ln \left(\begin{array}{c}
n_{h} \\
x_{h}
\end{array}\right)-d_{h} x+\left(n_{h}-x\right) \ln \left(1-e^{-d_{h}}\right)\right] .
$$

The triplet $(\alpha, \delta, \gamma)$ is estimated by maximization of $\ln L(\alpha, \delta, \gamma)$ taking into account the functional relationship from $(\alpha, \delta, \gamma)$ to separation rates. 
The resulting parameter estimates of our baseline estimation are displayed in Table 2, while Section 5 reports the outcomes of using alternative specifications. ${ }^{10}$ The parameter estimates are close to the findings of Christensen et al. (2005). The estimate $\gamma=1.268$ implies a search cost function that is not far from quadratic.

\begin{tabular}{lrr}
\multicolumn{2}{c}{ Table 2. Parameter estimates } \\
\hline \hline & Point estimate & Standard error \\
\hline$\alpha$ & 0.0098 & 0.0001 \\
$\delta$ & 0.2781 & 0.0001 \\
$\gamma$ & 1.2682 & 0.0071 \\
\hline \hline
\end{tabular}

The estimation produces a final vector of Poisson intensities $\left(\lambda s_{0}, \lambda s_{1}, \ldots, \lambda s_{N}\right)$, and hence from equations (4) and (5), a rate of non-employment $u$, and a wage distribution $G$. The rate of non-employment equals 0.295 , which to a large extent reflects the high job destruction rate, $\delta$. The rate of non-employment is very high compared to realistic unemployment levels. However, the estimate is more reasonable if including all people of working age who are out of employment temporarily, including those who have left the work force temporarily for various reasons, e.g., parental leave, supplementary education etc. In the sensitivity analysis of Section 5, we consider a modification of the job destruction process that brings the estimated rate of non-employment close to levels compatible with a rate of structural unemployment. See also the discussion in Christensen et al. (2005).

To evaluate the model's ability to reproduce the empirical wage distribution, we can compare the computed $g$-distribution with the wage distribution in the data. Figure 3 shows that these distributions are close to each other.

\section{Quantifying the Tax Distortions of the Allocation of La- bor}

This section uses the estimated model to measure the tax distortions of the allocation of labor. This is done by analyzing the effects of hypothetical tax reforms that change the tax system from one system $T$ with marginal tax rates $m_{i}$ (for example the initial tax system) to another tax system $\hat{T}$, involving new marginal tax rates $\hat{m}_{i}$. The changes in the tax liabilities and marginal tax rates are $\Delta T_{i}=\hat{T}_{i}-T_{i}$, and $\Delta m_{i}=\hat{m}_{i}-m_{i}$, respectively, where $\Delta T_{i+1}-\Delta T_{i}=\Delta m_{i}\left(w_{i+1}-w_{i}\right)$ for all $i$.

Since our focus is on the effects of marginal taxation of the employed on the mobility and allocation of labor, we only consider changes of the marginal tax rates, $m_{1}, \ldots, m_{N-1}$, along the intensive margin, while the participation tax along the extensive margin, $m_{0}=\left(T_{1}-T_{0}\right) / w_{1}$, is

\footnotetext{
${ }^{10}$ The Gauss program for the computation of the parameters are available from the authors upon request.
} 


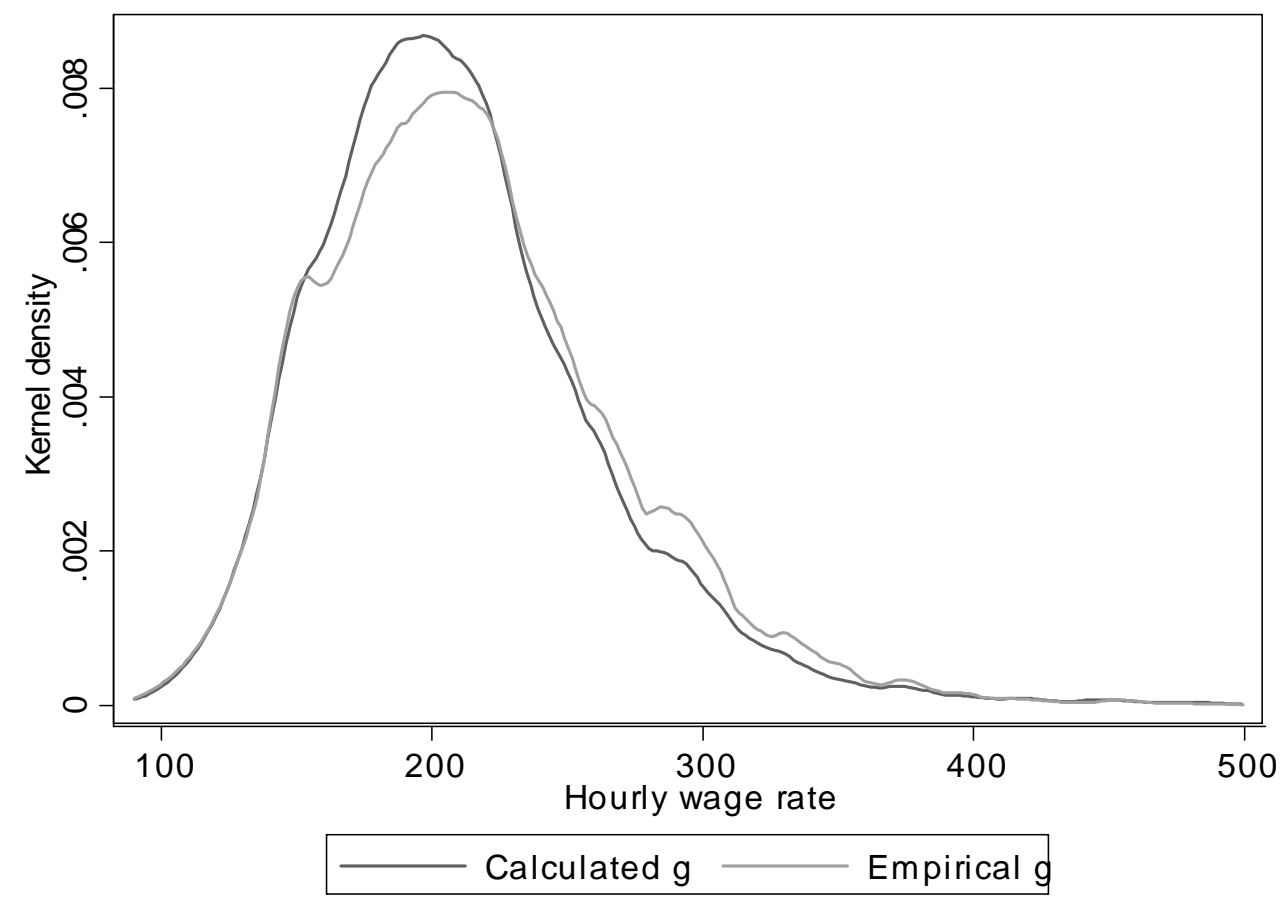

Figure 3: Calculated and empirical wage distribution

unchanged from the initial tax system in all of the experiments. ${ }^{11}$

Given the structural parameters (and $P_{i}$ ), we may compute the optimal Poisson search intensities $\lambda s_{i}$ and $\lambda \hat{s}_{i}$ associated with the tax system before and after the reform, respectively, using equation (16). From these search intensities, it is possible to derive pre-reform and post-reform rates of non-employment, $u$ and $\hat{u}$, from equation (4), wage distributions, $g$ and $\hat{g}$, from equation (5), aggregate income levels, $Y$ and $\hat{Y}$, from equation (13), private welfare levels, $W$ and $\hat{W}$, from equation (1), where the search $\operatorname{costs} c\left(s_{i}\right)$ are computed by inserting $c_{0}=\lambda^{1+1 / \gamma} / \alpha$ into equation (15), and tax revenues, $R$ and $\hat{R}$ from equation (10). Given this, it is possible to compute the change in aggregate income, $\Delta Y=\hat{Y}-Y$, the change in aggregate welfare/efficiency, $\Delta(W+R)=-\Delta D$, and the change in the dead-weight loss/excess burden of taxation relative to the mechanical change in government revenue, $\Delta D / \Delta M$, where the mechanical change in tax

\footnotetext{
${ }^{11}$ This is also an analytical necessity. The condition $w_{1}-T_{1}=w_{0}-T_{0}$ must hold both before and after a reform experiment. Since $w_{0}$ is a deep parameter (inferred from observation of $w_{1}$ and $T_{1}-T_{0}$ ), a change in $m_{0}$ would require a change in $w_{1}=w_{0} /\left(1-m_{0}\right)$. To compute the consequences would require a new domain of the $P$-distribution (from the new $w_{1}$ to $w_{N}$ ), but $P$ and its domain are exogenous in the analysis and can (in principle) only be observed for the existing $w_{1}$. In all the experiments we conduct, $T_{0}$ and $T_{1}$, and hence $w_{1}$ and $m_{0}$, are kept unchanged from the initial tax system.
} 
revenue is the change in government revenue before behavioral responses defined as

$$
\Delta M=(1-u) \sum_{i=1}^{N} \Delta T_{i} g_{i},
$$

where $u$ and $g_{i}$ are associated with the pre-reform tax system. For a tax reduction, $\Delta D / \Delta M$ measures the efficiency gain per dollar of mechanical loss in tax revenue.

\subsection{The marginal excess burden and the elasticity of taxable income}

First, we consider a small reform of the initial tax system where the marginal tax rates are reduced to create a one percent increase in the net-of-tax rates, $1-m_{i}$, everywhere along the intensive margin, that is, $\Delta m_{i}=-\Delta\left(1-m_{i}\right)=-0.01\left(1-m_{i}\right)$, and $\hat{m}_{i}=m_{i}+\Delta m_{i}$ for $i=1, \ldots N-1$. We then compute the elasticity of taxable income as $\varepsilon=(\Delta Y / Y) /\left[\Delta\left(1-m_{i}\right) /\left(1-m_{i}\right)\right]=100$. $\Delta Y / Y$. In our context, this estimate of the elasticity of taxable income measures the percentage increase in the income of the employed due to intensified search and labor mobility for a one percent increase in the net-of-tax rate of all employed. The elasticity estimate we obtain is $\varepsilon=0.30 .{ }^{12}$

Interestingly, we obtain a result very close to 0.30 if we use the formula (12) based on linear taxation to compute an approximate estimate of the elasticity. The efficiency gain from the considered reform is estimated to be 0.18 percent of aggregate income, that is, $-\Delta D / Y=0.0018$. The $\left(g_{i}\right.$-weighted) average effective marginal tax rate for our sample is $2 / 3$, so on average the netof-tax rate is 33.3 percent and therefore on average the absolute change in the marginal tax rate is 0.33 percentage points. From equation (12), we then get the approximate elasticity estimate: $\varepsilon=\frac{\Delta D}{Y} /\left(\frac{m}{1-m} \Delta m\right)=0.0018 /(2 \cdot 0.0033) \approx 0.27$. The fact that this estimate, based on an assumption of linear taxation, is so close to the above estimate, that accounts for the non-linearity of the tax system, reflects that the Danish tax system is indeed close to linear, as is also seen from Figure 1.

We may also use the reform experiment to compute the marginal excess burden of taxation as described above. When measured in proportion to the mechanical loss of tax revenue, we obtain an estimate of 87 percent. A marginal reduction in the tax rates, financed by lump sum taxation, yields an efficiency gain equal to 87 cent per dollar. Because we consider a small reform, this estimate also corresponds to the degree of self-financing of the tax cut. Thus, the increase in tax revenue from the behavioral response is 87 percent of the mechanical loss in tax revenue. The high marginal excess burden/degree of self financing reflects that effective marginal tax rates are high in Denmark (in 2006), ${ }^{13}$ and that the estimated elasticity is reasonably high.

\footnotetext{
${ }^{12}$ Smaller relative changes in the net-of-tax rate lead to almost the same elasticity estimate, showing that the considered reform is sufficiently small to approximate a marginal change in taxation.

${ }^{13}$ The Danish effective tax rates on labor income have been reduced in recent tax reforms, for example implying that the highest rate has dropped from 72 percent to 66 percent (Danish Economic Council, 2011).
} 


\subsection{The overall impact of marginal taxes on the allocation of labor and economic efficiency}

The structural approach enables us to consider tax systems that are not just marginally different from the existing tax system. In this subsection, we consider alternative tax systems $\hat{T}(m)$ indexed by $m$, where $\hat{T}_{0}(m)$ and $\hat{T}_{1}(m)$ are always the same as in the existing tax system, $\hat{T}_{0}(m)=T_{0}$ and $\hat{T}_{1}(m)=T_{1}$, and $\hat{T}_{i}(m)=T_{1}+m\left(w_{i}-w_{1}\right)$ for $i=2, \ldots, N$. That is, we consider tax systems with the same participation tax as in the existing system and some constant marginal tax rate, $m$, that applies to all wage levels above $w_{1}$. For $m$ we consider different alternative values, $0,0.01,0.02, \ldots, 1$. We analyze the effects of going from the existing tax system to specific

alternative systems $\hat{T}(m)$, and the effects of small changes from each $\hat{T}(m)$ to $\hat{T}(m+0.01)$, $m=0, \ldots, 0.99$.

First, we consider the effects of eliminating the progressivity of the existing tax system $T$ along the intensive margin. We do this by considering the alternative tax system $\hat{T}(\bar{m})$, where $\bar{m}$ is defined such that the mechanical change in tax revenue in equation (18) is zero when replacing the existing tax system $T$ with the new system $\hat{T}(\bar{m})$. This gives $\bar{m} \approx 0.6275$. The effects of implementing this system in the estimated, structural model are described in the first row of Table 3. It shows that the elimination of progressivity has negligible influence on non-employment, increases aggregate income by 0.8 percent, and gives an efficiency gain corresponding to 0.5 percent of initial income. These small magnitudes reflect again that the existing tax system is not far from being linear.

Second, we study a reform that completely eliminates marginal taxation along the intensive margin by replacing the existing tax system $T$ with $\hat{T}(0)$. The results in the third row of Table 3 show that the elimination of marginal taxation lowers non-employment by 13.3 percentage points and increases aggregate income by 28 percent. The effect on economic efficiency equals 12.4 percent of initial income and the change in the excess burden is around one third of the mechanical loss in tax revenue. A total efficiency cost of taxation equal to $1 / 3$ of the mechanical revenue change may seem small compared to the estimated marginal excess burden of almost 90 percent found in Subsection 4.1. However, as we show below this reflects the well-known fact that the marginal excess burden is increasing in the level of taxation.

Table 3 shows in the second row the effects of replacing the existing tax system $T$ with $\hat{T}(0.3)$, which may roughly represent a transition from a Scandinavian system with high marginal taxes to a system along the lines of low-tax OECD countries such as the United States. This reduces the rate of non-employment by around 10 percentage points, increases aggregate income by almost 20 percent (relative to the Scandinavian income level), and gives an efficiency gain measured in proportion to income of 9.9 percent. Thus, almost 80 percent of the efficiency loss from marginal 


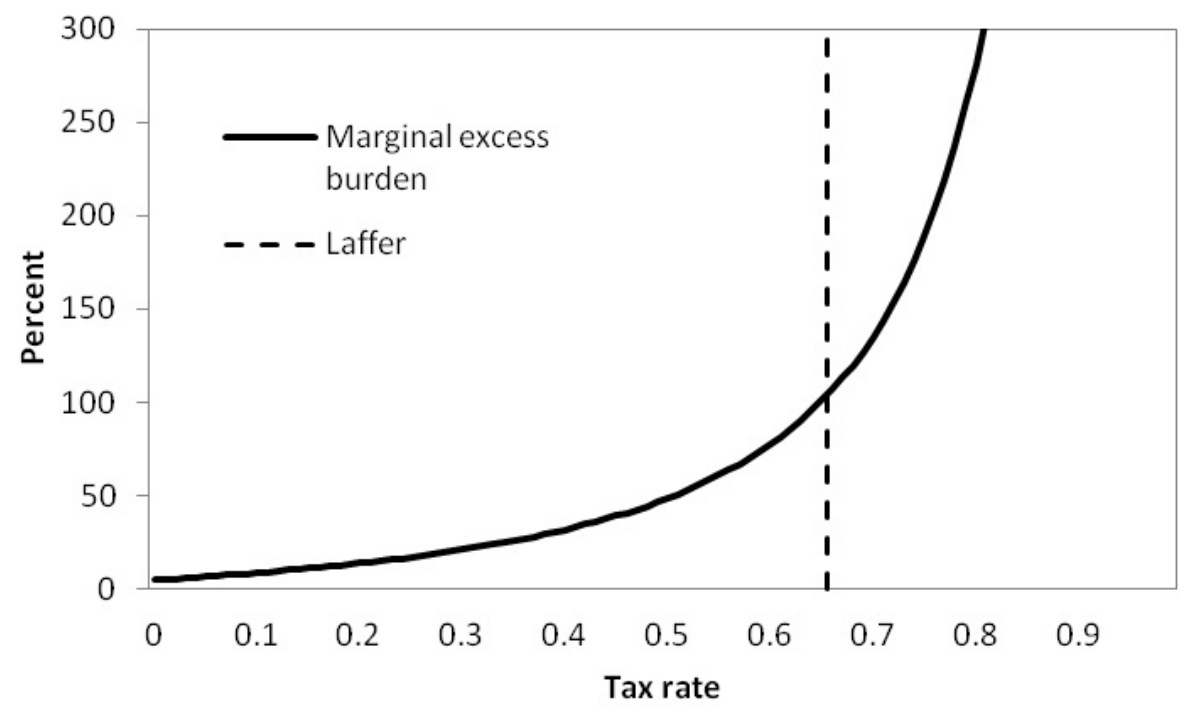

Figure 4: Marginal excess burden relative to mechanical revenue loss.

taxation (9.7\% divided by $12.4 \%$ ) would be eliminated by shifting from a Scandinavian tax system to the system of a low-tax OECD country according to these estimates. Of course, this should be balanced against the distributional impact of such a reform.

\begin{tabular}{ccccc}
\multicolumn{4}{c}{ Table 3. EfFects of implementing alternative new tax SYstems } \\
\hline \hline Tax rate & Non-employment & Income & Efficiency & Excess burden \\
$m$ & $\Delta u$ & $\Delta Y / Y$ & $-\Delta D / Y$ & $\Delta D / \Delta M$ \\
\hline $\bar{m}$ & -0.0001 & 0.0076 & 0.005 & - \\
0.3 & -0.093 & 0.193 & 0.099 & 0.526 \\
0.0 & -0.133 & 0.281 & 0.124 & 0.344 \\
\hline \hline
\end{tabular}

Understanding the relationship between the marginal excess burden and the tax rate is key to understanding the relationship between some of our results. Figure 4 illustrates how the marginal excess burden per dollar raised in tax revenue depends on the initial tax rate in the estimated model. To construct the graph, we have analyzed small tax reforms from each $\hat{T}(m)$ to $\hat{T}(m+0.01)$ for $m=0, \ldots, 0.99$. The graph shows an increasing and strictly convex relationship implying that the marginal excess burden of raising taxes is rather low at low levels of taxation and rather high at high levels of taxation. Note that the marginal excess burden is approximately equal to the degree of self-financing because we are considering small tax reforms, i.e., small changes in $m$. Thus, the graphs also shows that the Laffer rate (where $\Delta D / \Delta M$ is equal to one) in the linear tax system is approximately 66 percent. 


\section{Robustness}

The standard errors of Table 2 are very small and we have not reported confidence intervals of our further estimations of, e.g., $\varepsilon$, but these are very narrow. Still our results could be sensitive to potential mis-specifications. In this section we analyze the robustness of our quantitative results for various alternative and relevant specifications.

First, as mentioned in Subsection 3.3, the estimated rate of non-employment is rather high, which reflects a high job destruction rate. To account for the possibility that some of the job destruction in the data is not "true" job destruction because of measurement error, we consider the case where there could be a "data job destruction rate" equal to some multiplum, $q \delta$, of the true job destruction rate, $\delta$. The observed job separations of the estimation are governed by the "data separation rate"

$$
d_{h}^{\prime}=q \delta+\lambda s_{h}\left(1-P_{h}\right)
$$

but the optimal mobility efforts entering the estimation are governed by the true destruction rate $\delta$, which is also involved in the determination of the rate of non-employment via (4). For the parameter $q$, we consider three values: $q=1$, which is the baseline estimation, $q=3$, which gives a true job destruction rate in line with other empirical evidence for Denmark by Rosholm and Svarer (2004), ${ }^{14}$ and $q=6$, which gives a magnitude of the rate of non-employment around the level of the Danish structural unemployment rate, that may be considered as a lower estimate of the long run non-employment rate. For each $q$ considered the full estimation is redone and then the tax experiment with a common one percent increase in the marginal net-of-tax rates along the intensive margin is redone to derive an elasticity of earned income. Table 4 reports our results; all standard errors are very small and not reported.

\begin{tabular}{|c|c|c|c|}
\hline $\bar{q}$ & 1 & 3 & 6 \\
\hline$\alpha$ & 0.0098 & 0.0057 & 0.0041 \\
\hline$\delta$ & 0.2781 & 0.0936 & 0.0470 \\
\hline$\gamma$ & 1.2682 & 1.8717 & 2.6141 \\
\hline$u$ & 0.295 & 0.126 & 0.068 \\
\hline$\varepsilon$ & 0.30 & 0.20 & 0.17 \\
\hline$\Delta D / \Delta M$ & 0.87 & 0.57 & 0.49 \\
\hline
\end{tabular}

The fundamental parameter estimates are, of course, quite sensitive to $q$, but the derived elasticity is in all cases estimated to be in the interval $[0.17 ; 0.30]$. The efficiency gain relative to the mechanical revenue loss reaches from 87 percent down to approximately 50 percent.

\footnotetext{
${ }^{14}$ Using different data than here, Rosholm and Svarer observe the employment status of a one percent representative sample of Danish workers week by week over almost 10 years. They estimate a Poisson job destruction rate on weekly basis of 0.0019 . On annual basis this corresponds to a Poisson rate of approximately $0.0988(=52$ times $0.0019)$, which is around one third of the rate estimated here $(0.2781)$.
} 
Second, while annual labor income is well measured, ${ }^{15}$ there may be a concern about the use of annual hours in the construction of our wage rate measure. Annual hours are measured with less precision as they are based on information from the mandatory pension fund ATP, which collects a relatively modest mandatory pension fund payment from all workers in the Danish labor market. The payment depends on the number of hours worked, and so hours may be imputed, but overtime work is not accounted for and hours in part-time jobs are not precisely measured. This may be particularly problematic in our context where it is obviously of importance to have a precise measure of the change in wage rate associated with passing from one job to another. The measured changes could partly be due to changes in hours worked rather than only to payments per hour. To alleviate this concern we draw on the Wage Statistics Register (WSR or Lønstatistikken), which contains an alternative wage rate per hour reported by employers. This measure accounts explicitly for overtime work and part-time work. The downside of applying this measure is a rather low coverage rate. The 126,400 workplaces in our sample employ in total 1.4 million workers with an observed IDA wage rate, but only $60 \%$ of these workers have a reported WSR wage rate.

Our strategy, intended to adjust the IDA wage rate for imprecise measurement of hours, is to estimate a relationship between the two wage variables for the workers with information about both measures. Given the IDA wage rate, we can then impute the overtime and part-time adjusted wage rate for the full sample based on this relationship. In order to obtain a reliable relationship we first trim the sample of IDA wages. We drop the top and bottom one percent of the observations, and we also eliminate IDA wage rates that are deemed of low quality by Statistics Denmark. This reduces the number of observations to $54 \%$ of the original sample of workers. The WSR wage rate and the IDA wage rate are highly correlated with a correlation coefficient of 0.87 .

The next step is to estimate the relationship between the two measures. We use fractional polynomial regression, which is a very flexible way to estimate a relationship between two variables. ${ }^{16}$ This yields the following relationship

$$
E\left(w_{W S R} \mid w_{I D A}\right)=215.7+37.9\left(\left(\frac{w_{I D A}}{100}\right)^{2}-5.1\right)-13.7\left(\left(\frac{w_{I D A}}{100}\right)^{2} \ln \left(\frac{w_{I D A}}{100}\right)-4.1\right) .
$$

Using this functional form, Figure 5 plots the predicted adjusted wage rate against the IDA wage and also contains a $45^{\circ}$-line. The predicted wage rate is lower than than the IDA wage rate in most of the wage distribution, which is consistent with the existence of overtime work. At the bottom of the distribution the predicted wage rate is larger than the IDA wage rate, which is consistent with the WSR data better capturing part-time work.

\footnotetext{
${ }^{15}$ Annual labor income is based on tax return data. The Danish Tax Agency obtains third-party information from employers on nearly all labor income in Denmark, and tax evasion on labor income is almost zero (Kleven et al., 2011).

${ }^{16}$ We use the FRACPOLY routine in Stata.
} 


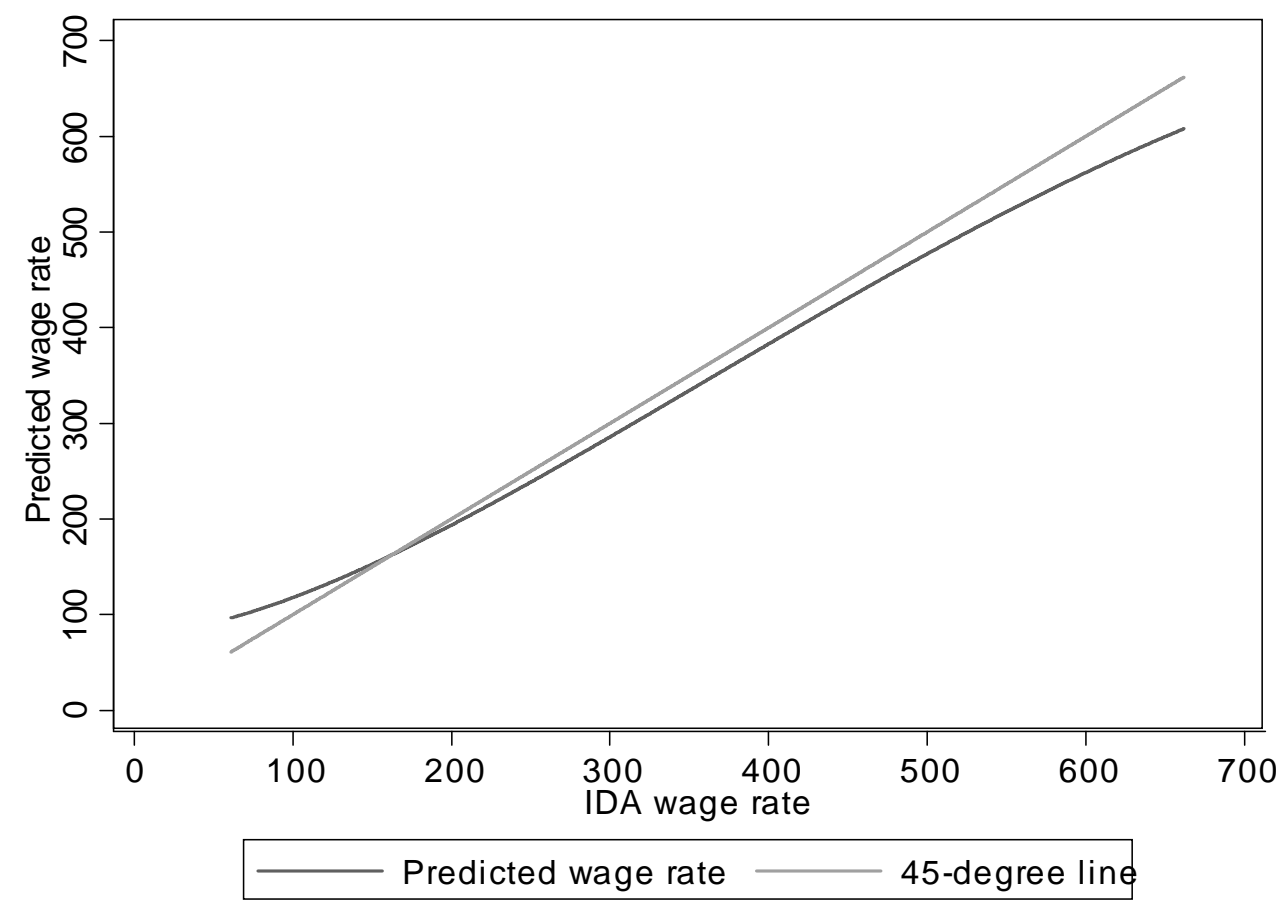

Figure 5: Predicted wage rate.

The final step in this robustness exercise is to replace the IDA wage rate with the predicted wage rate for all workers in the sample, calculate the average workplace wage rate, then estimate the model using this data set, and afterwards estimate once more the elasticity of taxable income. The full exercise is meant to eliminate hidden hours effects at job shifts and be left as closely as possible with a pure productivity effect on the hourly wage rate. Table 5 , first column shows that neither the estimates of structural parameters, nor the implied elasticity change to any substantial degree with this alternative specification.

Table 5. Robustness: Various alternative specifications

\begin{tabular}{cc|ccc|cc|c}
\hline \hline & Adjusted & \multicolumn{3}{|c|}{ Sample exclusion } & \multicolumn{2}{|c|}{ Wage cut off } & Particip. tax \\
& wage rate & Students & age $>50$ & Plant close & $w_{1}=80$ & $w_{1}=100$ & $m_{0}=0.82$ \\
\hline$\alpha$ & 0.0120 & 0.0060 & 0.0110 & 0.0060 & 0.0098 & 0.0095 & 0.0098 \\
$\delta$ & 0.2771 & 0.2673 & 0.2959 & 0.2491 & 0.2770 & 0.2792 & 0.2781 \\
$\gamma$ & 1.3519 & 1.1574 & 1.0781 & 0.9674 & 1.2541 & 1.2412 & 1.2682 \\
\hline$u$ & 0.274 & 0.354 & 0.298 & 0.325 & 0.282 & 0.314 & 0.295 \\
$\varepsilon$ & 0.29 & 0.33 & 0.27 & 0.27 & 0.28 & 0.31 & 0.30 \\
$\Delta D / \Delta M$ & 0.84 & 0.94 & 0.79 & 0.78 & 0.76 & 0.99 & 0.97 \\
\hline \hline
\end{tabular}

Third, a concern may be that entry-exit behavior of students, going in and out of the labor market and into part-time jobs, and of the oldest group of workers, where job exit to retirement is 
common, could be important for the results. We have therefore redone the analysis on restricted samples where students and individuals older than 50 are removed from the sample. Columns 3 and 4 report the results from these two sensitivity tests. The main conclusion is that the elasticity estimates of 0.27 and 0.33 are rather close to the baseline estimate of 0.30 . We have also tried to remove workers with less than 1 year of work experience. This gives an elasticity equal to $0.35 .{ }^{17}$

Fourth, we have removed closing plants from the analysis (column 5). This reduces the job destruction rate, but has little impact on the elasticity estimate, which becomes 0.27. If, in addition, we remove plants that downsize, identified as a 30 percent reduction or more in the number of workers as in Jacobson et al. (1993) then we obtain an elasticity of 0.25 .

Fifth, we consider two alternative values of the cutoff wage rate $w_{1}$, DKK 80 and DKK 100. In each alternative case, $w_{0}$ is adjusted to preserve $w_{0}=\left(1-m_{0}\right) w_{1}$, and the $P$-distribution is reestimated on the relevant domain. Columns 6 and 7 of Table 5 reveal only small differences in the parameters and the estimates of the elasticity of taxable income $\varepsilon$ lie in the narrow interval $[0.28 ; 0.31]$.

Sixth, the participation tax, $m_{0}=0.59$, was in the baseline estimation set at the level of the lowest marginal tax rates. The results of Kleven and Kreiner (2007) indicate that if the loss of unemployment/social benefits is included then the participation tax rate on the increase in income from zero to the lowest possible, full time work income is 82 percent. It is not clear that this is the right participation tax rate since many of the non-employed will only be entitled to these benefits for a limited period. However, to explore the possible consequences, we may set $m_{0}$ equal to 0.82 , keeping all other tax rates unchanged, and again adjust $w_{0}$ so that $w_{0}=\left(1-m_{0}\right) w_{1}$ etc. This means that the difference in net income between any two positions $i$ and $j$ is unchanged from the baseline estimation and hence the estimates of the structural parameters and the rate of non-employment as well as the elasticity of taxable income are also unchanged. The efficiency effect is affected, however, since now a decrease of marginal tax rates will cause a larger behavioral increase in tax revenue, because $T_{1}-T_{0}$ has increased, so there is a larger behavioral tax gain as non-employment is reduced. Column 8 of Table 5 shows that the estimate of the marginal excess burden (and therefore the degree of self financing) goes up to 97 percent, so in this case the considered tax experiment is close to a "Laffer change".

\footnotetext{
${ }^{17}$ We have also tried to run the analysis separately for men and women. This gives an elasticity of 0.35 for men and 0.18 for women. This would from an efficiency perspective, in isolation, call for higher tax rates on women than on men. However, with the anonymous tax systems used in practise, it is the overall elasticity of taxable income that is relevant for tax policy.
} 


\section{Concluding remarks}

In this paper, we apply a microeconometric, structural analysis to measure the distortionary effects of taxation on labor mobility and the long run allocation of labor. The analysis points to nonnegligible effects of taxes on labor mobility. We estimate a mobility-based elasticity of taxable income with respect to the net-of-tax rate in the range $0.15-0.35$. This is of the same magnitude as the estimates found in the empirical public finance literature using difference-in-difference type methods (Saez et al., 2012) and bunching at kink-points in the tax schedule (Chetty et al., 2011a) to measure the elasticity of taxable income. The aim of these methods is to capture all relevant behavioral responses to taxation, thereby obtaining a sufficient statistic for evaluating the efficiency effects of taxation. However, the methods do not provide a clear identification of the effects of taxation on labor mobility.

We have applied a workhorse, structural model of search and labor mobility for our analysis of the distortionary effects of taxation on the mobility of labor. The analysis relies on many strong, simplifying assumptions, as is common when working with structural models. For example, the empirical identification relies on independence of firm and worker components in wages and an exogenous distribution of job opportunities, and exploits only cross-sectional variation across individuals for identification.

The model focuses entirely on involuntary job losses leading to unemployment and voluntary job-to-job shifts involving upwards wage mobility. In reality labor market mobility is a complex phenomenon involving changes in geographical location and selling-buying houses, and workers may voluntarily move to a lower-paid job because of other characteristics of the job or the situation of the worker. Also, our analysis does not account for higher effort leading to promotions within firms, which may also lead to discrete jumps in earnings.

The most heroic assumption of the model is probably that all workers are assumed to be identical, implying that the underlying wage distribution is identical for all individuals. This is in stark contrast to the labor-leisure framework, underlying the standard identification methods used to estimate the elasticity of taxable income, where all variation in wages across individuals is assumed to be fully determined by underlying differences in ability levels, i.e., all workers with the same ability level will receive the exact same wage. Moreover, in that setting, a little more effort of the individual will always result in a little more wage income, rather than in a higher chance of receiving a discrete increase in wage income. Such discrete wage changes, normally observed in job shifts, are not well identified by the standard methods applied in the large empirical public finance literature. Thus, although our results rely on a number of strong assumptions, they do indicate, in our view, that the empirical public finance literature may be overlooking sizable labor 
mobility effects when measuring the behavioral responses to taxation and the elasticity of taxable income.

\section{A Derivation of equations (6) and (7)}

The derivation proceeds in three steps. In Step 1 we use equation (5) to derive expressions for $g_{1}, \ldots, g_{N}$, which are useful for computing the derivatives $\partial g_{j} / \partial g_{i}$ appearing in the first order conditions (3). In Step 2 we compute $\partial u / \partial s_{0}$ from (4) and $\partial g_{j} / \partial g_{i}$ from the expressions for $g_{j}$ obtained in Step 1. Finally, in Step 3, we insert the expressions for $\partial u / \partial s_{0}$ and $\partial g_{j} / \partial g_{i}$ of Step 2 into the first order conditions (2) and (3), and arrive at (6) and (7).

\section{A.1 Step 1}

We first show that equation (5) implies

$$
\begin{aligned}
g_{1} & =p_{1} \frac{\delta}{\delta+\lambda\left(1-P_{1}\right) s_{1}}, \text { and } \\
g_{i} & =\frac{\delta}{\delta+\lambda\left(1-P_{1}\right) s_{1}} p_{i} \prod_{j=1}^{i-1} \frac{\delta+\lambda\left(1-P_{j-1}\right) s_{j}}{\delta+\lambda\left(1-P_{j+1}\right) s_{j+1}},
\end{aligned}
$$

for $i=2, \ldots, N$. From equation (5), we have

$$
G_{1}=P_{1}-\frac{\lambda}{\delta}\left(1-P_{1}\right) s_{1} g_{1} .
$$

This may be written as

$$
g_{1}=p_{1}-\frac{\lambda}{\delta}\left(1-P_{1}\right) s_{1} g_{1}=p_{1} \frac{\delta}{\delta+\lambda\left(1-P_{1}\right) s_{1}}
$$

which is equation (A-1). From equation (5), we get

$$
\delta G_{i}+\lambda\left(1-P_{i}\right) \sum_{j=1}^{i} s_{j} g_{j}=\delta P_{i}
$$

and for $i \geq 2$, we have

$$
\delta G_{i-1}+\lambda\left(1-P_{i-1}\right) \sum_{j=1}^{i-1} s_{j} g_{j}=\delta P_{i-1} .
$$

By subtracting the second from the first of the two expressions above and splitting up summations, we obtain for $i \geq 2$ :

$$
\delta g_{i}+\lambda\left\{\left[\sum_{j=i+1}^{N} p_{i}\right]\left[\sum_{j=1}^{i-1} s_{j} g_{j}+s_{i} g_{i}\right]-\left[p_{i}+\sum_{j=i+1}^{N} p_{i}\right]\left[\sum_{j=1}^{i-1} s_{j} g_{j}\right]\right\}=\delta p_{i},
$$

or

$$
\delta g_{i}+\lambda\left\{\left[\sum_{j=i+1}^{N} p_{i}\right] s_{i} g_{i}-p_{i}\left[\sum_{j=1}^{i-1} s_{j} g_{j}\right]\right\}=\delta p_{i}
$$


or

$$
\left[\delta+\lambda\left(1-P_{i}\right) s_{i}\right] g_{i}=p_{i}\left(\delta+\lambda \sum_{j=1}^{i-1} s_{j} g_{j}\right)
$$

or

$$
g_{i}=p_{i} \frac{\delta+\lambda \sum_{j=1}^{i-1} s_{j} g_{j}}{\delta+\lambda\left(1-P_{i}\right) s_{i}}
$$

This is a recursive solution for $g_{i}, i=2, \ldots, N$ depending on $s_{1}, \ldots, s_{i}$ and $g_{1}, \ldots, g_{i-1}$. We derive a solution for $g_{i+1}$ only as a function of $g_{i}$ and $s_{i}$ and $s_{i+1}$. By leading (A-3), we get

$$
g_{i+1}=p_{i+1} \frac{\delta+\lambda \sum_{j=1}^{i} s_{j} g_{j}}{\delta+\lambda\left(1-P_{i+1}\right) s_{i+1}}=p_{i+1} \frac{\delta+\lambda \sum_{j=1}^{i-1} s_{j} g_{j}+\lambda s_{i} g_{i}}{\delta+\lambda\left(1-P_{i+1}\right) s_{i+1}} .
$$

From (A-3), we have $\lambda \sum_{j=1}^{i-1} s_{j} g_{j}=g_{i} \frac{\left(\delta+\lambda\left(1-P_{i}\right) s_{i}\right)}{p_{i}}-\delta$ which inserted in $g_{i+1}$ gives

$$
\left(\delta+\lambda\left(1-P_{i+1}\right) s_{i+1}\right) g_{i+1}=p_{i+1}\left(\frac{\delta+\lambda\left(1-P_{i}\right) s_{i}}{p_{i}}+\lambda s_{i}\right) g_{i}
$$

which gives

$$
g_{i+1}=\frac{p_{i+1}}{p_{i}} \frac{\delta+\lambda\left(1-P_{i-1}\right) s_{i}}{\delta+\lambda\left(1-P_{i+1}\right) s_{i+1}} g_{i} .
$$

By expanding this relationship, we obtain

$$
g_{2}=\frac{p_{2}}{p_{1}} \frac{\delta+\lambda\left(1-P_{0}\right) s_{1}}{\delta+\lambda\left(1-P_{2}\right) s_{2}} g_{1}=p_{2} \frac{\delta+\lambda\left(1-P_{0}\right) s_{1}}{\delta+\lambda\left(1-P_{2}\right) s_{2}} \frac{\delta}{\delta+\lambda\left(1-P_{1}\right) s_{1}},
$$

where we have used (A-1). By expanding further, we get

$$
\begin{aligned}
g_{3}= & \frac{p_{3}}{p_{2}} \frac{\delta+\lambda\left(1-P_{1}\right) s_{2}}{\delta+\lambda\left(1-P_{3}\right) s_{3}} g_{2} \\
= & p_{3} \frac{\delta+\lambda\left(1-P_{1}\right) s_{2}}{\delta+\lambda\left(1-P_{3}\right) s_{3}} \frac{\delta+\lambda\left(1-P_{0}\right) s_{1}}{\delta+\lambda\left(1-P_{2}\right) s_{2}} \frac{\delta}{\delta+\lambda\left(1-P_{1}\right) s_{1}} \\
& \ldots \\
g_{i}= & \frac{\delta}{\delta+\lambda\left(1-P_{1}\right) s_{1}} p_{i} \prod_{j=1}^{i-1} \frac{\delta+\lambda\left(1-P_{j-1}\right) s_{j}}{\delta+\lambda\left(1-P_{j+1}\right) s_{j+1}},
\end{aligned}
$$

which is $(\mathrm{A}-2)$.

\section{A.2 Step 2}

Here, we derive $\partial u / \partial s_{0}$ and $\partial g_{j} / \partial s_{i}$. Differentiation of equation (4) gives

$$
\frac{\partial u}{\partial s_{0}}=-\frac{\delta \lambda}{\left(\lambda s_{0}+\delta\right)^{2}}=-\frac{\lambda}{\lambda s_{0}+\delta} u
$$

We show below that differentiation of equations (A-1) and (A-2) give

$$
\frac{\partial g_{j}}{\partial s_{i}}=\left\{\begin{array}{cc}
0 & \text { for } j<i \\
-g_{i} \frac{\lambda\left(1-P_{i}\right)}{\delta+\lambda\left(1-P_{i}\right) s_{i}}<0 & \text { for } j=i \\
\frac{\lambda \delta p_{i}}{\left(\delta+\lambda\left(1-P_{i-1}\right) s_{i}\right)\left(\delta+\lambda\left(1-P_{i}\right) s_{i}\right)} g_{j}>0 & \text { for } j>i
\end{array}\right.
$$


We start by changing indices in (A-2). This gives

$$
g_{j}=\frac{\delta}{\delta+\lambda\left(1-P_{1}\right) s_{1}} p_{j} \prod_{h=1}^{j-1} \frac{\delta+\lambda\left(1-P_{h-1}\right) s_{h}}{\delta+\lambda\left(1-P_{h+1}\right) s_{h+1}} .
$$

We see directly that $\partial g_{j} / \partial s_{i}=0$ for $j<i$.

By differentiating (A-7) with respect to $s_{i}$ for $j=i$, we get

$$
\begin{aligned}
\frac{\partial g_{i}}{\partial s_{i}} & =-\frac{\delta}{\delta+\lambda\left(1-P_{1}\right) s_{1}} p_{i}\left(\prod_{h=1}^{i-2} \frac{\delta+\lambda\left(1-P_{h-1}\right) s_{h}}{\delta+\lambda\left(1-P_{h+1}\right) s_{h+1}}\right) \frac{\delta+\lambda\left(1-P_{i-2}\right) s_{i-1}}{\left(\delta+\lambda\left(1-P_{i}\right) s_{i}\right)^{2}} \lambda\left(1-P_{i}\right) \\
& =-\frac{\delta}{\delta+\lambda\left(1-P_{1}\right) s_{1}} p_{i}\left(\prod_{h=1}^{i-2} \frac{\delta+\lambda\left(1-P_{h-1}\right) s_{h}}{\delta+\lambda\left(1-P_{h+1}\right) s_{h+1}}\right) \frac{\delta+\lambda\left(1-P_{i-2}\right) s_{i-1}}{\delta+\lambda\left(1-P_{i}\right) s_{i}} \frac{\lambda\left(1-P_{i}\right)}{\delta+\lambda\left(1-P_{i}\right) s_{i}} \\
& =-\frac{\delta}{\delta+\lambda\left(1-P_{1}\right) s_{1}} p_{i}\left(\prod_{h=1}^{i-1} \frac{\delta+\lambda\left(1-P_{h-1}\right) s_{h}}{\delta+\lambda\left(1-P_{h+1}\right) s_{h+1}}\right) \frac{\lambda\left(1-P_{i}\right)}{\delta+\lambda\left(1-P_{i}\right) s_{i}} \\
& =-g_{i} \frac{\lambda\left(1-P_{i}\right)}{\delta+\lambda\left(1-P_{i}\right) s_{i}}
\end{aligned}
$$

We now differentiate (A-7) with respect to $s_{i}$ for $j>i$. For $i=1$, we have

$$
\begin{aligned}
\frac{\partial g_{j}}{\partial s_{1}}= & -\delta \frac{\lambda\left(1-P_{1}\right)}{\left(\delta+\lambda\left(1-P_{1}\right) s_{1}\right)^{2}} p_{j} \prod_{h=1}^{j-1} \frac{\delta+\lambda\left(1-P_{h-1}\right) s_{h}}{\delta+\lambda\left(1-P_{h+1}\right) s_{h+1}} \\
& +\frac{\delta}{\delta+\lambda\left(1-P_{1}\right) s_{1}} p_{j} \frac{\lambda}{\delta+\lambda s_{1}} \prod_{h=1}^{j-1} \frac{\delta+\lambda\left(1-P_{h-1}\right) s_{h}}{\delta+\lambda\left(1-P_{h+1}\right) s_{h+1}} \\
= & {\left[\frac{\lambda}{\delta+\lambda s_{1}}-\frac{\lambda\left(1-P_{1}\right)}{\delta+\lambda\left(1-P_{1}\right) s_{1}}\right] g_{j} }
\end{aligned}
$$

For $i>1$, we get

$$
\begin{aligned}
\frac{\partial g_{j}}{\partial s_{i}} & =\frac{\delta}{\delta+\lambda\left(1-P_{1}\right) s_{1}} p_{j}\left(\frac{\lambda\left(1-P_{i-1}\right)}{\delta+\lambda\left(1-P_{i-1}\right) s_{i}}-\frac{\lambda\left(1-P_{i}\right)}{\delta+\lambda\left(1-P_{i}\right) s_{i}}\right) \prod_{h=1}^{j-1} \frac{\delta+\lambda\left(1-P_{h-1}\right) s_{h}}{\delta+\lambda\left(1-P_{h+1}\right) s_{h+1}} \\
& =\left(\frac{\lambda\left(1-P_{i-1}\right)}{\delta+\lambda\left(1-P_{i-1}\right) s_{i}}-\frac{\lambda\left(1-P_{i}\right)}{\delta+\lambda\left(1-P_{i}\right) s_{i}}\right) g_{j} \\
& =\frac{\lambda \delta\left(P_{i}-P_{i-1}\right)}{\left(\delta+\lambda\left(1-P_{i-1}\right) s_{i}\right)\left(\delta+\lambda\left(1-P_{i}\right) s_{i}\right)} g_{j} \\
& =\frac{\lambda \delta p_{i}}{\left(\delta+\lambda\left(1-P_{i-1}\right) s_{i}\right)\left(\delta+\lambda\left(1-P_{i}\right) s_{i}\right)} g_{j}
\end{aligned}
$$

This formula also holds for $i=1$, which is easily seen by comparing the second equality to the previous expression for $\partial g_{j} / \partial s_{1}$.

\section{A.3 Step 3}

Consider optimal search effort at $i=N$. In this case, the condition (3) becomes

$$
-c^{\prime}\left(s_{N}\right) g_{N}+\left[w_{N}-T_{N}-c\left(s_{N}\right)\right] \frac{\partial g_{N}}{\partial s_{N}}=0
$$


From equation (A-6), we have $\partial g_{N} / \partial s_{N}=0$, because $P_{N}=1$. Hence, $c^{\prime}\left(s_{N}\right)=0$ giving $s_{N}=0$ in (6).

Next, we derive (7). We first consider $i \geq 1$. Note that in equation (3) one can let the summation start in $i$ since from equation (A-6), $\partial g_{j} / \partial s_{i}=0$ for $j<i$. By isolating $c^{\prime}\left(s_{i}\right)$ from (3), we then obtain

$$
c^{\prime}\left(s_{i}\right)=\frac{\left[w_{i}-T_{i}-c\left(s_{i}\right)\right] \frac{\partial g_{i}}{\partial s_{i}}+\sum_{j=i+1}^{N}\left[w_{j}-T_{j}-c\left(s_{j}\right)\right] \frac{\partial g_{j}}{\partial s_{i}}}{g_{i}} .
$$

By inserting the derivatives $\partial g_{j} / \partial s_{i}$ from (A-6), we get

$$
\begin{aligned}
c^{\prime}\left(s_{i}\right)= & -\left[w_{i}-T_{i}-c\left(s_{i}\right)\right] \frac{\lambda\left(1-P_{i}\right)}{\delta+\lambda\left(1-P_{i}\right) s_{i}}+\frac{\lambda \delta p_{i}}{\left(\delta+\lambda\left(1-P_{i-1}\right) s_{i}\right)\left(\delta+\lambda\left(1-P_{i}\right) s_{i}\right)} \times \\
& \frac{1}{g_{i}} \sum_{j=i+1}^{N}\left[w_{j}-T_{j}-c\left(s_{j}\right)\right] g_{j}
\end{aligned}
$$

or

$$
\begin{aligned}
c^{\prime}\left(s_{i}\right)= & -\left[w_{i}-T_{i}-c\left(s_{i}\right)\right] \frac{\lambda\left(1-P_{i}\right)}{\delta+\lambda\left(1-P_{i}\right) s_{i}}+\frac{\lambda \delta p_{i}}{\left(\delta+\lambda\left(1-P_{i-1}\right) s_{i}\right)\left(\delta+\lambda\left(1-P_{i}\right) s_{i}\right)} \times \\
& \frac{1}{g_{i}}\left(\left[w_{i+1}-T_{i+1}-c\left(s_{i+1}\right)\right] g_{i+1}+\sum_{j=i+2}^{N}\left[w_{j}-T_{j}-c\left(s_{j}\right)\right] g_{j}\right)
\end{aligned}
$$

By leading equation (A-8), we obtain

$$
\begin{aligned}
c^{\prime}\left(s_{i+1}\right)= & -\left[w_{i+1}-T_{i+1}-c\left(s_{i+1}\right)\right] \frac{\lambda\left(1-P_{i+1}\right)}{\delta+\lambda\left(1-P_{i+1}\right) s_{i+1}} \\
& +\frac{\lambda \delta p_{i+1}}{\left(\delta+\lambda\left(1-P_{i}\right) s_{i+1}\right)\left(\delta+\lambda\left(1-P_{i+1}\right) s_{i+1}\right)} \frac{1}{g_{i+1}} \sum_{j=i+2}^{N}\left[w_{j}-T_{j}-c\left(s_{j}\right)\right] g_{j}
\end{aligned}
$$

or

$$
\begin{gathered}
\sum_{j=i+2}^{N}\left[w_{j}-T_{j}-c\left(s_{j}\right)\right] g_{j}=\frac{\left(\delta+\lambda\left(1-P_{i}\right) s_{i+1}\right)\left(\delta+\lambda\left(1-P_{i+1}\right) s_{i+1}\right) g_{i+1}}{\lambda \delta p_{i+1}} c^{\prime}\left(s_{i+1}\right) \\
+\left[w_{i+1}-T_{i+1}-c\left(s_{i+1}\right)\right] \frac{\lambda\left(1-P_{i+1}\right)\left(\delta+\lambda\left(1-P_{i}\right) s_{i+1}\right) g_{i+1}}{\lambda \delta p_{i+1}}
\end{gathered}
$$

By substituting (A-10) into (A-9) and multiplying by $\left[\delta+\lambda\left(1-P_{i}\right) s_{i}\right] / \lambda$, we get

$$
\begin{gathered}
\frac{\delta+\lambda\left(1-P_{i}\right) s_{i}}{\lambda} c^{\prime}\left(s_{i}\right)=-\left[w_{i}-T_{i}-c\left(s_{i}\right)\right]\left(1-P_{i}\right) \\
+\frac{\delta p_{i}}{\delta+\lambda\left(1-P_{i-1}\right) s_{i}} \frac{g_{i+1}}{g_{i}}\left[w_{i+1}-T_{i+1}-c\left(s_{i+1}\right)\right] \\
+\frac{\delta p_{i}}{\delta+\lambda\left(1-P_{i-1}\right) s_{i}} \frac{g_{i+1}}{g_{i}} \frac{\left(\delta+\lambda\left(1-P_{i}\right) s_{i+1}\right)\left(\delta+\lambda\left(1-P_{i+1}\right) s_{i+1}\right)}{\lambda \delta p_{i+1}} c^{\prime}\left(s_{i+1}\right) \\
+\frac{\delta p_{i}}{\delta+\lambda\left(1-P_{i-1}\right) s_{i}} \frac{g_{i+1}}{g_{i}}\left[w_{i+1}-T_{i+1}-c\left(s_{i+1}\right)\right] \frac{\lambda\left(1-P_{i+1}\right)\left(\delta+\lambda\left(1-P_{i}\right) s_{i+1}\right)}{\lambda \delta p_{i+1}}
\end{gathered}
$$


From equation (A-4), we have

$$
\frac{g_{i+1}}{g_{i}}=\frac{p_{i+1}}{p_{i}} \frac{\delta+\lambda\left(1-P_{i-1}\right) s_{i}}{\delta+\lambda\left(1-P_{i+1}\right) s_{i+1}}
$$

By substituting this relationship into the above expression, we get

$$
\begin{gathered}
\frac{\delta+\lambda\left(1-P_{i}\right) s_{i}}{\lambda} c^{\prime}\left(s_{i}\right)=-\left[w_{i}-T_{i}-c\left(s_{i}\right)\right]\left(1-P_{i}\right) \\
+\delta p_{i+1} \frac{1}{\delta+\lambda\left(1-P_{i+1}\right) s_{i+1}}\left[w_{i+1}-T_{i+1}-c\left(s_{i+1}\right)\right] \\
+\frac{1}{\delta+\lambda\left(1-P_{i+1}\right) s_{i+1}} \frac{\left(\delta+\lambda\left(1-P_{i}\right) s_{i+1}\right)\left(\delta+\lambda\left(1-P_{i+1}\right) s_{i+1}\right)}{\lambda} c^{\prime}\left(s_{i+1}\right) \\
+\frac{1}{\delta+\lambda\left(1-P_{i+1}\right) s_{i+1}}\left[w_{i+1}-T_{i+1}-c\left(s_{i+1}\right)\right] \frac{\lambda\left(1-P_{i+1}\right)\left(\delta+\lambda\left(1-P_{i}\right) s_{i+1}\right)}{\lambda}
\end{gathered}
$$

or

$$
\begin{gathered}
\frac{\delta+\lambda\left(1-P_{i}\right) s_{i}}{\lambda} c^{\prime}\left(s_{i}\right)=-\left[w_{i}-T_{i}-c\left(s_{i}\right)\right]\left(1-P_{i}\right) \\
+\delta p_{i+1} \frac{1}{\delta+\lambda\left(1-P_{i+1}\right) s_{i+1}}\left[w_{i+1}-T_{i+1}-c\left(s_{i+1}\right)\right] \\
+\frac{\left(\delta+\lambda\left(1-P_{i}\right) s_{i+1}\right)}{\lambda} c^{\prime}\left(s_{i+1}\right) \\
+\frac{1}{\delta+\lambda\left(1-P_{i+1}\right) s_{i+1}}\left[w_{i+1}-T_{i+1}-c\left(s_{i+1}\right)\right]\left(1-P_{i+1}\right)\left(\delta+\lambda\left(1-P_{i}\right) s_{i+1}\right)
\end{gathered}
$$

or

$$
\frac{\delta+\lambda\left(1-P_{i}\right) s_{i}}{\lambda\left(1-P_{i}\right)} c^{\prime}\left(s_{i}\right)-\frac{\delta+\lambda\left(1-P_{i}\right) s_{i+1}}{\lambda\left(1-P_{i}\right)} c^{\prime}\left(s_{i+1}\right)=\left[w_{i+1}-T_{i+1}-c\left(s_{i+1}\right)\right]-\left[w_{i}-T_{i}-c\left(s_{i}\right)\right]
$$

or

$$
\begin{aligned}
& \delta c^{\prime}\left(s_{i}\right)+\lambda\left(1-P_{i}\right) s_{i} c^{\prime}\left(s_{i}\right)-\left(\delta+\lambda\left(1-P_{i}\right) s_{i+1}\right) c^{\prime}\left(s_{i+1}\right) \\
= & \lambda\left\{\left[w_{i+1}-T_{i+1}-c\left(s_{i+1}\right)\right]-\left[w_{i}-T_{i}-c\left(s_{i}\right)\right]\right\}\left(1-P_{i}\right)
\end{aligned}
$$

By adding $\lambda\left(1-P_{i}\right) s_{i+1} c^{\prime}\left(s_{i}\right)$ and subtracting $\lambda\left(1-P_{i}\right) s_{i} c^{\prime}\left(s_{i}\right)$ on both sides, we get

$$
\begin{aligned}
& \delta c^{\prime}\left(s_{i}\right)+\lambda\left(1-P_{i}\right) s_{i+1} c^{\prime}\left(s_{i}\right)-\left(\delta+\lambda\left(1-P_{i}\right) s_{i+1}\right) c^{\prime}\left(s_{i+1}\right) \\
= & \lambda\left\{\left[w_{i+1}-T_{i+1}-c\left(s_{i+1}\right)\right]-\left[w_{i}-T_{i}-c\left(s_{i}\right)\right]\right\}\left(1-P_{i}\right) \\
& -\lambda\left(1-P_{i}\right) s_{i} c^{\prime}\left(s_{i}\right)+\lambda\left(1-P_{i}\right) s_{i+1} c^{\prime}\left(s_{i}\right)
\end{aligned}
$$

or

$$
\begin{aligned}
c^{\prime}\left(s_{i}\right)= & \lambda \frac{\left[w_{i+1}-T_{i+1}\right]-\left[w_{i}-T_{i}\right]-\left[c\left(s_{i+1}\right)-c\left(s_{i}\right)\right]+\left(s_{i+1}-s_{i}\right) c^{\prime}\left(s_{i}\right)}{\delta+\lambda s_{i+1}\left(1-P_{i}\right)}\left(1-P_{i}\right) \\
& +c^{\prime}\left(s_{i+1}\right)
\end{aligned}
$$


Next, we show that (A-11) also applies for $i=0$. From equations (2) and (A-5), we get

$$
-c^{\prime}\left(s_{0}\right)-\frac{\lambda}{\lambda s_{0}+\delta}\left[w_{0}-T_{0}-c\left(s_{0}\right)-\left[w_{1}-T_{1}-c\left(s_{1}\right)\right] g_{1}-\sum_{j=2}^{N}\left[w_{j}-T_{j}-c\left(s_{j}\right)\right] g_{j}\right]=0
$$

or

$$
\begin{aligned}
0= & -\left(\lambda s_{0}+\delta\right) c^{\prime}\left(s_{0}\right)-\lambda\left[w_{0}-T_{0}-c\left(s_{0}\right)\right]+\lambda\left[w_{1}-T_{1}-c\left(s_{1}\right)\right] g_{1} \\
& +\lambda \sum_{j=2}^{N}\left[w_{j}-T_{j}-c\left(s_{j}\right)\right] g_{j}
\end{aligned}
$$

Equation (A-10) holds also for $i=0$, because it has been leaded. With $P_{0}=0$ this gives

$$
\begin{aligned}
\sum_{j=2}^{N}\left[w_{j}-T_{j}-c\left(s_{j}\right)\right] g_{j}= & \frac{\left(\delta+\lambda s_{1}\right)\left(\delta+\lambda\left(1-P_{1}\right) s_{1}\right) g_{1}}{\lambda \delta p_{1}} c^{\prime}\left(s_{1}\right) \\
& +\left[w_{1}-T_{1}-c\left(s_{1}\right)\right] \frac{\lambda\left(1-P_{1}\right)\left(\delta+\lambda s_{1}\right) g_{1}}{\lambda \delta p_{1}}
\end{aligned}
$$

By inserting this sum in the above equation, we arrive at

$$
\begin{aligned}
0= & -\left(\lambda s_{0}+\delta\right) c^{\prime}\left(s_{0}\right)-\lambda\left[w_{0}-T_{0}-c\left(s_{0}\right)\right] \\
& +\lambda\left[w_{1}-T_{1}-c\left(s_{1}\right)\right] \frac{\delta+\left(1-P_{1}\right) \lambda s_{1}}{\delta p_{1}} g_{1} \\
& +\frac{\left(\delta+\lambda s_{1}\right)\left(\delta+\lambda\left(1-P_{1}\right) s_{1}\right) g_{1}}{\delta p_{1}} c^{\prime}\left(s_{1}\right)
\end{aligned}
$$

Inserting $g_{1}$ from equation (A-1) gives

$$
\begin{aligned}
0= & -\left(\lambda s_{0}+\delta\right) c^{\prime}\left(s_{0}\right)-\lambda\left[w_{0}-T_{0}-c\left(s_{0}\right)\right]+\lambda\left[w_{1}-T_{1}-c\left(s_{1}\right)\right] \\
& +\left(\delta+\lambda s_{1}\right) c^{\prime}\left(s_{1}\right)
\end{aligned}
$$

or

$$
\begin{aligned}
c^{\prime}\left(s_{0}\right)= & \lambda \frac{\left[w_{1}-T_{1}-c\left(s_{1}\right)\right]-\left[w_{0}-T_{0}-c\left(s_{0}\right)\right]+\left(s_{1}-s_{0}\right) c^{\prime}\left(s_{0}\right)}{\delta+\lambda s_{1}} \\
& +c^{\prime}\left(s_{1}\right)
\end{aligned}
$$

This shows that (A-11) also holds for $i=0$ with $P_{0}=0$.

From (A-11) follows by multiplying on both sides by $\delta+\lambda s_{i+1}\left(1-P_{i}\right)$ etc.

$$
\begin{aligned}
c^{\prime}\left(s_{i}\right)= & \lambda \frac{\left[w_{i+1}-T_{i+1}\right]-\left[w_{i}-T_{i}\right]-\left[c\left(s_{i+1}\right)-c\left(s_{i}\right)\right]+s_{i+1} c^{\prime}\left(s_{i+1}\right)-s_{i} c^{\prime}\left(s_{i}\right)}{\delta}\left(1-P_{i}\right) \\
& +c^{\prime}\left(s_{i+1}\right)
\end{aligned}
$$

which is (7). 


\section{B Derivation of Equation (11)}

We first insert $W$ and $R$ from equations (1) and (10) into the expression (9) for $D$. We then total differentiate this expression thereby obtaining the change in the dead-weight loss of taxation $d D$ as a functions of the changes in tax liabilities $d T_{i}$, the induced changes in search effort $d s_{i}$, and the changes in the distributional parameters $d u$ and $d g_{i}$. By arranging the terms appropriately, $d D$ can be split into three components in a way well-known from the theory of taxation

$$
d D=\left.d D\right|_{\text {Mechanical }}+\left.d D\right|_{\text {Behavior on utility }}+\left.d D\right|_{\text {Behavior on tax revenue }},
$$

where

$$
\left.d D\right|_{\text {Mechanical }}=u \cdot d T_{0}+(1-u) \sum_{i=1}^{N} d T_{i} g_{i}-u \cdot d T_{0}-(1-u) \sum_{i=1}^{N} d T_{i} g_{i}
$$

is the mechanical effect on $R+W$, and

$$
\left.d D\right|_{\text {Behavior on utility }}=\sum_{i=0}^{N} \frac{\partial W}{\partial s_{i}} d s_{i}
$$

is the effect on utility $(W)$ from changed behavior and

$$
\left.d D\right|_{\text {Behavior on tax revenue }}=-\left(T_{0}-\sum_{i=1}^{N} T_{i} g_{i}\right) d u-(1-u) \sum_{i=1}^{N} T_{i} \cdot d g_{i}
$$

is the effect on tax revenue from behavioral responses. The mechanical effect is obviously zero and from the optimum conditions of the worker, $\partial W / \partial s_{i}=0$, it follows that the behavioral effect on utility is also zero. Thus,

$$
d D=\left.d D\right|_{\text {Behavior on tax revenue }}=\left(\sum_{i=1}^{N}\left[T_{i}-T_{0}\right] g_{i}\right) \frac{\partial u}{\partial s_{0}} d s_{0}-(1-u) \sum_{j=1}^{N} \sum_{i=j}^{N} T_{i} \frac{\partial g_{i}}{\partial s_{j}} d s_{j},
$$

where we have used that $\partial g_{i} / \partial s_{j}=0$ for $i<j$ according to equation (A-6). Since $g$ is a probability distribution, we have $\sum_{i=1}^{N} \frac{\partial g_{i}}{\partial s_{j}} d s_{j}=0$, which after using $\partial g_{i} / \partial s_{j}=0$ for $i<j$ implies $\sum_{i=1}^{N} \frac{\partial g_{i}}{\partial s_{j}} d s_{j}=\sum_{i=j}^{N} \frac{\partial g_{i}}{\partial s_{j}} d s_{j}$. By subtracting $T_{j} \sum_{i=j}^{N} \frac{\partial g_{i}}{\partial s_{j}} d s_{j}=0$ on the RHS of the above equation, we obtain (11).

\section{Derivation of Equation (12)}

For $T_{i}=T_{0}+m \cdot w_{i}$, equation (11) becomes

$d D=m\left(\sum_{i=1}^{N} w_{i} g_{i}\right) \frac{\partial u}{\partial s_{0}} \frac{\partial s_{0}}{\partial(1-m)} d(1-m)-(1-u) m \sum_{j=1}^{N} \sum_{i=j+1}^{N}\left(w_{i}-w_{j}\right) \frac{\partial g_{i}}{\partial s_{j}} \frac{\partial s_{j}}{\partial(1-m)} d(1-m)$

or

$d D=-\frac{m}{1-m}\left[\left(\sum_{i=1}^{N} w_{i} g_{i}\right) \frac{\partial u}{\partial s_{0}} \frac{\partial s_{0}}{\partial(1-m)}-(1-u) \sum_{j=1}^{N} \sum_{i=j+1}^{N}\left(w_{i}-w_{j}\right) \frac{\partial g_{i}}{\partial s_{j}} \frac{\partial s_{j}}{\partial(1-m)}\right] \frac{1-m}{Y} Y \cdot d m$. 
To establish (12), we need to show that

$$
\varepsilon=-\left[\frac{\partial u}{\partial s_{0}} \frac{\partial s_{0}}{\partial(1-m)}\left(\sum_{i=1}^{N} w_{i} g_{i}\right)-(1-u) \sum_{j=1}^{N} \sum_{i=j+1}^{N}\left(w_{i}-w_{j}\right) \frac{\partial g_{i}}{\partial s_{j}} \frac{\partial s_{j}}{\partial(1-m)}\right] \frac{1-m}{Y}
$$

From the definition of $Y$, we compute

$$
\frac{\partial Y}{\partial(1-m)}=-\left[\frac{\partial u}{\partial s_{0}} \frac{\partial s_{0}}{\partial(1-m)} \sum_{i=1}^{N} w_{i} g_{i}-(1-u) \sum_{j=1}^{N} \sum_{i=j}^{N} w_{i} \frac{\partial g_{i}}{\partial s_{j}} \frac{\partial s_{j}}{\partial(1-m)}\right]
$$

Consider the last term and split it up

$$
\sum_{j=1}^{N} \sum_{i=j}^{N} w_{i} \frac{\partial g_{i}}{\partial s_{j}} \frac{\partial s_{j}}{\partial(1-m)}=\sum_{j=1}^{N} \sum_{i=j+1}^{N} w_{i} \frac{\partial g_{i}}{\partial s_{j}} \frac{\partial s_{j}}{\partial(1-m)}+\sum_{j=1}^{N} w_{j} \frac{\partial g_{j}}{\partial s_{j}} \frac{\partial s_{j}}{\partial(1-m)}
$$

Since from (A-6) a change in $s_{j}$ only affects $g_{i}$ for $i \geq j$, and since changes $\partial g_{i}$ in $g_{i}$ must ad up to zero over all $i$, we have

$$
\frac{\partial g_{j}}{\partial s_{j}} \frac{\partial s_{j}}{\partial(1-m)}+\sum_{i=j+1}^{N} \frac{\partial g_{i}}{\partial s_{j}} \frac{\partial s_{j}}{\partial(1-m)}=0
$$

implying that

$$
\frac{\partial g_{j}}{\partial s_{j}} \frac{\partial s_{j}}{\partial(1-m)}=-\sum_{i=j+1}^{N} \frac{\partial g_{i}}{\partial s_{j}} \frac{\partial s_{j}}{\partial(1-m)} .
$$

Inserting into (C-14) gives

$$
\begin{aligned}
\sum_{j=1}^{N} \sum_{i=j}^{N} w_{i} \frac{\partial g_{i}}{\partial s_{j}} \frac{\partial s_{j}}{\partial(1-m)} & =\sum_{j=1}^{N} \sum_{i=j+1}^{N} w_{i} \frac{\partial g_{i}}{\partial s_{j}} \frac{\partial s_{j}}{\partial(1-m)}-\sum_{j=1}^{N} \sum_{i=j+1}^{N} w_{j} \frac{\partial g_{i}}{\partial s_{j}} \frac{\partial s_{j}}{\partial(1-m)} \\
& =\sum_{j=1}^{N} \sum_{i=j+1}^{N}\left(w_{i}-w_{j}\right) \frac{\partial g_{i}}{\partial s_{j}} \frac{\partial s_{j}}{\partial(1-m)}
\end{aligned}
$$

Inserting this for the last term in $(\mathrm{C}-13)$ gives

$$
\frac{d Y}{\partial(1-m)}=-\left[\frac{\partial u}{\partial s_{0}} \frac{\partial s_{0}}{\partial(1-m)} \sum_{i=1}^{N} w_{i} g_{i}-(1-u) \sum_{j=1}^{N} \sum_{i=j+1}^{N}\left(w_{i}-w_{j}\right) \frac{\partial g_{i}}{\partial s_{j}} \frac{\partial s_{j}}{\partial(1-m)}\right]
$$

Hence,

$$
\begin{aligned}
\varepsilon & =\frac{d Y}{\partial(1-m)} \frac{1-m}{Y} \\
& =-\left[\frac{\partial u}{\partial s_{0}} \frac{\partial s_{0}}{\partial(1-m)} \sum_{i=1}^{N} w_{i} g_{i}-(1-u) \sum_{j=1}^{N} \sum_{i=j+1}^{N}\left(w_{i}-w_{j}\right) \frac{\partial g_{i}}{\partial s_{j}} \frac{\partial s_{j}}{\partial(1-m)}\right] \frac{1-m}{Y}
\end{aligned}
$$

which is indeed (C-12). 


\section{References}

[1] Botero, J.C., S. Djankov, R. La Porta, F. Lopez-De-Silanes and A. Shleifer (2004). "The Regulation of Labor", Quarterly Journal of Economics 119(4), 1339-1382.

[2] Burdett, K. (1978). "A Theory of Employee Job Search and Quit Rates", American Economic Review 68, 212-220.

[3] Chetty, R. (2009). "Is the Taxable Income Elasticity Sufficient to Calculate Deadweight Loss? The Implications of Evasion and Avoidance." American Economic Journal: Economic Policy $1,31-52$.

[4] Chetty, R. (2012). "Bounds on Elasticities with Optimization Frictions: A Synthesis of Micro and Macro Evidence on Labor Supply." Econometrica 80(3): 969-1018.

[5] Chetty, R., J. Friedman, T. Olsen and L. Pistaferri (2011a). "Adjustment Costs, Firm Responses, and Micro vs. Macro Labor Supply Elasticities: Evidence from Danish Tax Records." Quarterly Journal of Economics 126, 749-804.

[6] Chetty, R., A. Guren, D. Manoli and A. Weber (2011b). "Are Micro and Macro Labor Supply Elasticities Consistent? A Review of Evidence on the Intensive and Extensive Margins." American Economic Review Papers and Proceedings 101, 471-75.

[7] Christensen, B. J., R. Lentz, D. T. Mortensen, G. R. Neumann and A. Werwatz, 2005. "On-the-Job Search and the Wage Distribution." Journal of Labor Economics 23, 31-58.

[8] Dahl, C.M., J.R. Munch and D.le Maire (2013). "Wage Dispersion and Decentralization of Wage Bargaining", Journal of Labor Economics 31, 501-533.

[9] Danish Economic Council (2011). "The Danish Economy, Fall 2011." Rosendahls-Schultz: Copenhagen.

[10] Eissa, N., H.J. Kleven and Claus T. Kreiner (2008). "Evaluation of Four Tax Reforms in the United States: Labor Supply and Welfare Effects for Single Mothers." Journal of Public Economics 92, 795-816.

[11] Feldstein, M. (1995). "The Effect of Marginal Tax Rates on Taxable Income: A Panel Study of the 1986 Tax Reform Act." Journal of Political Economy 103, 551-572.

[12] Feldstein, M. (1999). "Tax Avoidance and the Deadweight Loss of the Income Tax." Review of Economics and Statistics 81, 674-80. 
[13] Feldstein, M. and M.V. Wrobel (1998). "Can state taxes redistribute income?" Journal of Public Economics 68, 369-396.

[14] Gentry, W. M. and R. G. Hubbard, 2004. "The Effects of Progressive Income Taxation on Job Turnover." Journal of Public Economics 88, 2301-2322.

[15] Hayek, F. A., 1945. "The Use of Knowledge in Society." American Economic Review 35, $521-530$.

[16] Immervoll, H., H.J. Kleven, C.T. Kreiner and E. Saez (2007). "Welfare Reform in European Countries: A Micro-Simulation Analysis". Economic Journal 117, 1-44.

[17] Jacobson, L.S., R.J. LaLonde and D.G. Sullivan (1993). "Earnings Losses of Displaced Workers". American Economic Review 83, 685-709.

[18] Kleven, H.J. and C.T. Kreiner (2005). "Labor Supply Behavior and the Design of Tax and Transfer Policy". Danish Journal of Economics 143, 2005, 321-358.

[19] Kleven, H. J. and C. T. Kreiner (2006). "Beskatning af Arbejdsindkomst i Danmark." Chapter 7 in Torben Tranæs (ed.), Skat, Arbejde og Lighed, The Rockwool Foundation, Gyldendal, Copenhagen.

[20] Kleven, H.J. M. Knudsen, C.T. Kreiner, S. Pedersen and E. Saez (2011). "Unwilling or Unable to Cheat? Evidence from a Tax Audit Experiment in Denmark. Econometrica 79, 651-692.

[21] Kleven, H.J., C. Landais, E. Saez and E.A. Schultz (2014). "Migration and Wage Effects of Taxing Top Earners: Evidence from the Foreigners' Tax Scheme in Denmark." Quarterly Journal of Economics 129, 333-378.

[22] Kleven, H.J. and E. Schultz (2013). "Estimating Taxable Income Responses using Danish Tax Reforms." Forthcoming in.American Economic Journal: Economic Policy.

[23] Rosholm, M. and M. Svarer. "Endogenous Wage Dispersion in a search-matching Model", Labour Economics 11, 623-645.

[24] Saez, E. (2010). "Do Taxpayers Bunch at Kink Points?" American Economic Journal: Economic Policy 2 (3): 180-212.

[25] Saez, E., J. Slemrod, and S.H. Giertz (2012). "The Elasticity of Taxable Income with Respect to Marginal Tax Rates: A Critical Review." Journal of Economic Literature 50(1), 3-50.

[26] Slemrod, J. and W. Kopczuk (2002). "The Optimal Elasticity of Taxable Income." Journal of Public Economics 84, 91-112. 
[27] Spencer, B. and H. Selin (2014). "Bunching and Non-Bunching at Kink Points of the Swedish Tax Schedule." Journal of Public Economics, 109, 36-49.

[28] Topel, R.H. and M.P. Ward (1992). "Job Mobility and the Careers of Young Men." Quaterly Journal of Economics, 439-479. 